\title{
Atomic data for radioactive elements Ra I, Ra II, Ac I and Ac II and application to their detection in HD 101065 and HR 465`
}

\author{
P. Quinet ${ }^{1,2}$, C. Argante ${ }^{1}$, V. Fivet $^{1}$, C. Terranova ${ }^{1}$, A. V. Yushchenko ${ }^{3,4}$, and É. Biémont ${ }^{1,2}$
}

\author{
1 Astrophysique et Spectroscopie, Université de Mons-Hainaut, 7000 Mons, Belgium \\ e-mail: quinet@umh.ac.be \\ 2 IPNAS (Bât. B15), Université de Liège, Sart Tilman, 4000 Liège, Belgium \\ 3 Astrophysical Research Center for the Structure and Evolution of the Cosmos, Sejong University, Seoul 143-747, South Korea \\ 4 Astronomical Observatory, Odessa National University, Park Shevchenko, Odessa 65014, Ukraine
}

Received 14 June 2007 / Accepted 13 August 2007

\section{ABSTRACT}

Radiative data for transitions of astrophysical interest in radioactive elements Ra I, Ra II, Ac I and Ac II have been computed using a semi-empirical relativistic Hartree-Fock approach including core polarization effects. Most of the oscillator strengths reported in the present paper are new. A possible detection of radium (Ra II) and actinium (Ac II) in the spectrum of the stars HD 101065 and HR 465 is examined and discussed.

Key words. atomic data - stars: chemically peculiar

\section{Introduction}

In astrophysics, the first detection of short-lived radioactive elements in stellar atmospheres was made by Merrill (1952) who identified Tc I lines in the spectra of S-type stars. A few years later, Przybylski (1961) discovered a star (HD 101065) with properties that placed it far outside of the known limits of the stellar peculiarities. More precisely, Cowley et al. (2000) performed abundance determination of this star for 54 elements and found that lanthanides were overabundant by $4-5$ dex. The overabundance of thorium and uranium was also reported in the same paper while Cowley (2003) and Cowley et al. (2004) confirmed with a high degree of confidence the presence of lines of radioactive technetium and promethium. In addition, Gopka et al. (2004) presented the results on new identification of the lines of all radioactive elements with atomic numbers from $Z=84$ to $Z=99$, except for $Z=85$ (At) and $Z=87$ (Fr). The presence of these heavy short-lived radioactive elements in Przybylski's star is enigmatic. Cowley et al. (2004) proposed that some unrecognized processes, such as flare activities, were taking place in the atmosphere of the star. On the other hand, Gopka et al. (2004) suggested that the presence of elements with $Z<92$ is due to the natural radioactive decay of thorium and uranium in the upper atmosphere while the existence of elements with $Z>92$ could be due to neutron capture in the stratified layers of the atmosphere with large overabundance of thorium and uranium. A discussion about possible explanation for the existence of short-lived radioactive elements in stellar atmospheres can also be found in Goriely \& Arnould (2001), Gopka et al. (2006) and Yushchenko et al. (2006, 2007). In a recent paper, Goriely (2007) has stressed the importance of spallation nucleosynthesis compared to diffusion processes as a possible explanation of the peculiar abundances spectroscopically determined at the surface of HD 101065. Although it remains difficult to

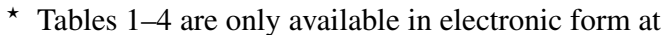
http: //WwW . aanda.org disentangle the effect of both processes theoretically, this conclusion does not necessarily reduce the role of the diffusion processes which have proven to be of first importance to understand the atmosphere of CP stars. As stressed by Goriely (2007), "the contribution of the nuclear process would be greatly strengthened if spectroscopic observation could confirm the presence of short-lived radioelements at the surface of CP stars and, if confirmed, hopefully in a close future provide abundance determination for these clear tracers of nuclear activity". Unfortunately, for most of the 72 lines of radioactive elements listed by Gopka et al. (2004) in the spectrum of HD 101065, oscillator strengths are not known. As a first attempt to fill in this gap, we report in the present paper atomic structure calculations for transitions of astrophysical interest in Ra I, Ra II $(Z=88)$, Ac I and Ac II $(Z=89)$

\section{Available atomic data}

According to the NIST compilation (Moore 1971), very few energy levels are known in Ra I. In fact, 13 even- and 28 odd-parity levels have been identified by Rasmussen (1934a) with the revisions suggested by Russel (1934) on the basis of the comparison of $\mathrm{Ra}$ I with the analogous Be I, Mg I, Ca I, Sr I and Ba I spectra. These levels were established from 69 classified lines from $2955.65 \AA$ to $9932.21 \AA$ and interpreted as belonging to the $7 \mathrm{~s}^{2}$, 7s7p, 7s6d, 7s8s, 6d7p, 7s8p, 7p 2 , 7s7d, 7s9s, 7s5f, 7s6f, 7s7f and 7s8f configurations. In Ra II, Rasmussen (1933, 1934b) classified 64 lines between $1888.7 \AA$ and $9453.57 \AA$, from a hollowcathode source and stressed the similarity of this spectrum with the $\mathrm{Ba}$ II one. This gave rise to well-established $n \mathrm{~s}(n=7-11)$, $n \mathrm{p}(n=7-9), n \mathrm{~d}(n=6-12), n \mathrm{f}(n=5-7)$ and $n \mathrm{~g}(n=5-11)$ Rydberg series.

For Ac I and Ac II, the energy levels reported in the NIST compilation (Moore 1971) are based on the observation of the emission spectrum of actinium due to Meggers et al. (1957) who analyzed arc and hollow-cathode spectrograms made at 
the Argonne National Laboratory by Fred et al. (1955). In these spectra, 87 Ac I lines, with wavelengths ranging from $2968.82 \AA$ to $7866.10 \AA$, were classified as combinations among 6 even and 34 odd energy levels while 226 Ac II lines, with wavelelengths from $2261.75 \AA$ to $7886.82 \AA$, were classified as combinations of 27 even and 38 odd levels. These levels were interpreted as belonging to the $6 d 7 s^{2}, 6 d^{2} 7 s, 7 s^{2} 7 p, 6 d 7 s 7 p, 6 d^{2} 7 p$ configurations (Ac I) and to the $7 \mathrm{~s}^{2}, 7 \mathrm{~s} 6 \mathrm{~d}, 6 \mathrm{~d}^{2}, 7 \mathrm{~s} 7 \mathrm{p}, 6 \mathrm{~d} 7 \mathrm{p}, 7 \mathrm{~s} 5 \mathrm{f}$, $7 \mathrm{~s} 8 \mathrm{~s}$ and $5 \mathrm{f} 7 \mathrm{p}$ configurations (Ac II).

In a more recent compilation on actinide elements due to Blaise \& Wyart (1992), the spectrum of Ac I was not reanalyzed. For Ac II, however, the energy levels from the early analysis by Meggers et al. (1957) were reinvestigated by the parametric Slater-Condon method which led to a few changes in the theoretical assignments. The studied configurations were $7 \mathrm{~s}^{2}+6 \mathrm{~d}^{2}+$ $6 d 7 s+5 f^{2}+5 f 7 p$ and $5 f 6 d+5 f 7 s+6 d 7 p+7 s 7 p$, respectively. This led to reject the two levels $5 \mathrm{f} 7 \mathrm{p}^{3} \mathrm{G}_{5}$ and $6 \mathrm{~d} 5 \mathrm{f}^{3} \mathrm{H}_{5}^{\circ}$ reported in the NIST compilation (Moore 1971) and to find four new even levels between 56491 and $64285 \mathrm{~cm}^{-1}$ from the 80 lines which remained unclassified after the analysis by Meggers et al. (1957).

Available transition rates and lifetime values in neutral and singly ionized radium and actinium are very sparse.

In the case of $\mathrm{Ra} \mathrm{I}$, oscillator strengths were calculated for the $7 s^{2}-7 s 7 p$ transitions using the relativistic pseudo-potential approach (Hafner \& Schwarz 1978), the multiconfiguration Dirac-Fock method (Bruneau 1984) and the relativistic local spin density functional (Sen \& Puri 1989a). More recently, the multiconfiguration Dirac-Hartree-Fock model was employed to compute oscillator strengths for the $7 \mathrm{~s}^{2}{ }^{1} \mathrm{~S}_{0}-7 \mathrm{~s} 7 \mathrm{p}{ }^{1} \mathrm{P}_{1}^{\circ}$ electric dipole and the $7 \mathrm{~s}^{2}{ }^{1} \mathrm{~S}_{0}-7 \mathrm{~s} 6 \mathrm{~d}{ }^{3} \mathrm{D}_{2}$ electric quadrupole transitions (Bieron et al. 2004) while relativistic Hartree-Fock method (Dzuba et al. 2000) and many-body perturbation theory (Dzuba \& Ginges 2006) were used to compute transition probabilities for lines connecting the low-lying states belonging to the $7 \mathrm{~s}^{2}$, $7 \mathrm{~s} 7 \mathrm{p}$ and $7 \mathrm{~s} 6 \mathrm{~d}$ configurations. The lifetime of the $7 \mathrm{~s} 7 \mathrm{p}{ }^{3} \mathrm{P}_{1}^{\circ}$ level was experimentally determined by Scielzo et al. (2006) by measuring the exponential decay of fluorescence after illuminating a thermal atomic beam with pulses of laser light.

For Ra II, the only attempts to obtain radiative data are due to Lindgård \& Nielsen (1977), who considered a simple Coulomb approximation and to Sen \& Puri (1989b), Glushkov (1991) and Glushkov et al. (1996), who used essentially model-potential approaches. In one recent work (Biémont et al. 2004), oscillator strengths were computed for the first ions along the francium isoelectronic sequence, including Ra II, using the pseudorelativistic Hartree-Fock and the fully relativistic Dirac-Fock methods.

In the case of actinium, the only available results were obtained by Sen \& Puri (1989a) who used the relativistic spin density functional approach to compute oscillator strengths for the $7 s^{2}-7 s 7 p$ transition array in Ac II. However, to our knowledge, no transition rates were published for Ac I.

\section{Energy levels}

For heavy neutral and lowly ionized atoms such as those considered in the present work, accurate calculations of atomic structure should allow for both intravalence and core-valence correlation. In addition relativistic effects must normally play an important role. A method which has appeared as a suitable compromise between a gratifying accuracy of the results (tested by comparison with accurate laser lifetime measurements), the moderate complexity of the codes used and the ability to obtain many new results in a limited period of time, is the relativistic Hartree-Fock (HFR) technique as described by Cowan (1981) but modified by us for the inclusion of core-polarization (CPOL) effects. In this approach (HFR+CPOL), most of the intravalence correlation is represented within a configuration interaction scheme while core-valence correlation is described by a core-polarization model potential and a correction to the dipole operator depending upon two parameters, i.e. the dipole polarizability of the ionic core, $\alpha_{\mathrm{d}}$, and the cut-off radius, $r_{\mathrm{c}}$ (for details see e.g. Quinet et al. 1999). Although based on the Schrödinger equation, this method takes the most important relativistic effects, such as the mass-velocity contribution and the Darwin correction, into account.

\subsection{Ra I}

We have introduced in the model explicit intravalence interactions between the configurations $7 s^{2}+7 s 8 s+7 s 9 s+7 s 6 d+$ $7 s 7 d+7 s 8 d+7 s 9 d+6 d 8 s+6 d 9 s+6 d 7 d+6 d 8 d+6 d 9 d+$ $6 d^{2}+7 p^{2}+7 d^{2}+5 f^{2}+5 f 7 p+5 f 8 p+5 f 9 p+5 f 6 f+5 f 7 f$ $+5 f 8 f+5 f 9 f$ (for the even parity) and $7 s 7 p+7 s 8 p+7 s 9 p+$ $7 s 5 f+7 s 6 f+7 s 7 f+7 s 8 f+7 s 9 f+6 d 7 p+6 d 8 p+6 d 9 p+$ $7 p 7 d+7 p 8 d+7 p 9 d+7 p 8 s+7 p 9 s+6 d 5 f+6 d 6 f+6 d 7 f+$ $6 d 8 f+6 d 9 f+5 f 7 d+5 f 8 d+5 f 9 d+5 f 8 s+5 f 9 s$ (for the odd parity). Core-polarization effects were included using the dipole polarizability, $\alpha_{\mathrm{d}}$, equal to $18.62 a_{0}^{3}$, as tabulated by Fraga et al. (1976) for the ionic core $\mathrm{Ra}^{2+}$ while the cut-off radius, $r_{\mathrm{c}}$, was chosen to be equal to $2.07 a_{0}$ which corresponds to the expectation value of $r$ for the outermost core orbital $\left(6 p^{6}\right)$ as calculated with Cowan's codes. The HFR+CPOL method was combined with a least-squares optimization routine minimizing the discrepancies between calculated and experimental energy levels compiled by Moore (1971). More precisely, for the even parity, the average energies, $E_{\mathrm{av}}$, the exchange Slater integrals, $G^{2}(\mathrm{~s}, \mathrm{~d})$, and the spin-orbit parameters, $\zeta_{\mathrm{d}}$, corresponding to the $7 \mathrm{~s} 6 \mathrm{~d}$ and $7 \mathrm{~s} 7 \mathrm{~d}$ configurations were adjusted while only the average energies of $7 \mathrm{~s}^{2}, 7 \mathrm{~s} 8 \mathrm{~s}, 7 \mathrm{~s} 9 \mathrm{~s}$ and $6 \mathrm{~d}^{2}$ were optimized. It should be noted here that the average energy parameter of $6 \mathrm{~d}^{2}$ was fitted instead of the one corresponding to $7 \mathrm{p}^{2}$ because the three energy levels (at 31248.84, 32214.84 and $32941.13 \mathrm{~cm}^{-1}$ ) identified in the NIST compilation (Moore 1971) as belonging to $7 \mathrm{p}^{2}$ were predicted, in our calculations, as mainly belonging to $6 \mathrm{~d}^{2}$, the $7 \mathrm{p}^{2}$ configuration appearing a few thousands of $\mathrm{cm}^{-1}$ above (around $37000 \mathrm{~cm}^{-1}$ ). This prediction is confirmed when comparing Ra I with the analogous Ba I spectrum in which the $6 \mathrm{p}^{2}$ configuration is situated $\sim 10000 \mathrm{~cm}^{-1}$ above $5 \mathrm{~d}^{2}$. For the odd parity, all the radial parameters $\left(E_{\mathrm{av}}, F^{k}, G^{k}, \zeta_{\mathrm{nl}}\right)$ corresponding to the $7 \mathrm{~s} 7 \mathrm{p}$, $7 \mathrm{~s} 8 \mathrm{p}$ and $6 \mathrm{~d} 7 \mathrm{p}$ configurations were adjusted while only average energies were fitted for $7 \mathrm{~s} 5 \mathrm{f}, 7 \mathrm{~s} 6 \mathrm{f}, 7 \mathrm{~s} 7 \mathrm{f}$ and $7 \mathrm{~s} 8 \mathrm{f}$ configurations. The standard deviations, as defined by Cowan (1981) were found to be equal to $194 \mathrm{~cm}^{-1}$ for the even parity (13 levels and 10 variable parameters) and $260 \mathrm{~cm}^{-1}$ for the odd parity (28 levels and 16 adjustable parameters).

\section{2. $R a$ II}

The physical HFR+CPOL model used here was exactly the same as the one described in our previous paper related to Fr-like ions Ra II, Ac III, Th IV and U VI (Biémont et al. 2004). In this model, all the $n \mathrm{~s}, n \mathrm{p}, n \mathrm{~d}, n \mathrm{f}, n \mathrm{~g}$ and $n \mathrm{~h}$ configurations up to $n=12$ were included while core-polarization corrections were considered with $\alpha_{\mathrm{d}}=18.62 a_{0}^{3}$ and $r_{\mathrm{c}}=2.07 a_{0}$. The semiempirical process was then performed using all the experimental 
energy levels taken from the NIST compilation (Moore 1971). More precisely, the average energies $\left(E_{\mathrm{av}}\right)$ and the spin-orbit parameters $\left(\zeta_{\mathrm{nl}}\right)$ were adjusted to reproduce exactly the doublet energy levels belonging to the $n \mathrm{~s}(n=7-12), n \mathrm{p}(n=7-9), n \mathrm{~d}$ $(n=6-12), n f(n=5-7)$ and $n \mathrm{~g}(n=5-11)$ configurations.

\subsection{Ac I}

For this atom, intravalence correlation was considered by means of the inclusion of the following configurations in the HFR model $: 6 d 7 s^{2}+6 d^{2} 7 s+6 d^{2} 8 s+6 d^{3}+6 d^{2} 7 d+7 s^{2} 7 d+7 s^{2} 8 s$ $+6 \mathrm{~d} 7 \mathrm{p}^{2}+7 \mathrm{~s} 7 \mathrm{p}^{2}+7 \mathrm{p}^{2} 7 \mathrm{~d}+7 \mathrm{p}^{2} 8 \mathrm{~s}+5 \mathrm{f} 6 \mathrm{~d} 7 \mathrm{p}+5 \mathrm{f} 6 \mathrm{~d} 8 \mathrm{p}+5 \mathrm{f} 7 \mathrm{~s} 7 \mathrm{p}$ $+5 f 7 s 8 p+5 f 7 p 7 d+5 f 7 p 8 s+6 d 7 s 7 d+6 d 7 s 8 s+6 d 7 p 8 p+$ $6 \mathrm{~d} 7 \mathrm{~d} 8 \mathrm{~s}+7 \mathrm{~s} 7 \mathrm{p} 8 \mathrm{p}+7 \mathrm{~s} 7 \mathrm{~d} 8 \mathrm{~s}$ (even parity) and $7 \mathrm{~s}^{2} 7 \mathrm{p}+7 \mathrm{~s}^{2} 8 \mathrm{p}+$ $7 \mathrm{p}^{3}+5 \mathrm{f}^{2} \mathrm{~d}^{2}+6 \mathrm{~d}^{2} 7 \mathrm{p}+6 \mathrm{~d}^{2} 8 \mathrm{p}+5 \mathrm{f} 7 \mathrm{~s}^{2}+5 \mathrm{f} 7 \mathrm{p}^{2}+7 \mathrm{p}^{2} 8 \mathrm{p}+5 \mathrm{f} 6 \mathrm{~d} 7 \mathrm{~s}$ $+5 f 6 d 8 s+5 f 6 d 7 d+5 f 7 s 7 d+5 f 7 s 8 s+5 f 7 p 8 p+6 d 7 s 7 p+$ $6 d 7 s 8 p+6 d 7 p 7 d+6 d 7 p 8 s+6 d 7 d 8 p+6 d 8 s 8 p+7 s 7 p 7 d+$ $7 s 7 p 8 s+7 s 7 d 8 p+7 s 8 s 8 p$ (odd parity). Core-polarization effects were considered with the dipole polarizability tabulated by Fraga et al. (1976) for the $\mathrm{Ac}^{3+}$ ion, i.e. $\alpha_{\mathrm{d}}=13.50 a_{0}^{3}$, and the cut-off radius taken from Cowan's code as the expectation value of $r$ for the $6 \mathrm{p}^{6}$ orbital in actinium, i.e. $r_{\mathrm{c}}=1.97 a_{0}$. For the even parity, the six experimental energy levels belonging to the $6 \mathrm{~d} 7 \mathrm{~s}^{2}{ }^{2} \mathrm{D}$ and $6 \mathrm{~d}^{2}\left({ }^{3} \mathrm{~F}\right) 7 \mathrm{~s}{ }^{4} \mathrm{~F}$ multiplets tabulated by Blaise \& Wyart (1992) allowed us to adjust the average energies and spin-orbit parameters corresponding to these configurations. Unfortunately, for the odd parity, despite the fact that all but two energy levels of the $6 \mathrm{~d} 7 \mathrm{~s} 7 \mathrm{p}$ configuration are reported in Blaise \& Wyart's compilation, we were unable to obtain a reasonable fit by adjusting the corresponding radial parameters. More precisely, when adjusting all the radial parameters (average energy, spin-orbit parameters and electrostatic integrals) corresponding to $6 \mathrm{~d} 7 \mathrm{~s} 7 \mathrm{p}$, the average deviation between calculated and experimental energy levels was found to be equal to $853 \mathrm{~cm}^{-1}$, this value being only reduced to $826 \mathrm{~cm}^{-1}$ when introducing the "illegal- $k$ " effective operators (Cowan 1981). This could be due to the fact that one or several experimental energies are affected by large uncertainties. Another reason could be that the $6 d^{2} 7 p$ configuration, which is expected to interact strongly with some $6 \mathrm{~d} 7 \mathrm{~s} 7 \mathrm{p}$ levels, is unsufficiently known to allow a simultaneous adjustment of all parameters, including configuration interaction integrals, corresponding to both configurations. Other low-lying configurations such as $7 \mathrm{~s}^{2} 7 \mathrm{p}, 7 \mathrm{~s}^{2} 8 \mathrm{p}, 5 \mathrm{f} 7 \mathrm{~s}^{2}$ could also play a role. Although included in our physical model, the fact that these latter configurations are completely unknown experimentally could explain the poor quality of the fitting process. Consequently, in the present work, only average energies were adjusted for $6 \mathrm{~d} 7 \mathrm{~s} 7 \mathrm{p}$ and $6 \mathrm{~d}^{2} 7 \mathrm{p}$ configurations. However, in order to optimize the final results, the theoretical transition energies were replaced by experimental values when computing the oscillator strengths.

\subsection{Ac II}

The Ac II ion belongs to the radium isoelectronic sequence. Consequently, the same set of interacting configurations as the one used for Ra I was explicitly included in the physical model. For the core-polarization parameters, we used the same values as for Ac I, i.e. $\alpha_{\mathrm{d}}=13.50 a_{0}^{3}$ and $r_{\mathrm{c}}=1.97 a_{0}$. The semi-empirical procedure was applied to the $7 \mathrm{~s}^{2}, 7 \mathrm{~s} 8 \mathrm{~s}, 7 \mathrm{~s} 6 \mathrm{~d}$, $6 \mathrm{~d}^{2}$ even configurations and to the $7 \mathrm{~s} 7 \mathrm{p}, 7 \mathrm{~s} 5 \mathrm{f}, 6 \mathrm{~d} 7 \mathrm{p}, 6 \mathrm{~d} 5 \mathrm{f}$ odd configurations for which all the corresponding radial parameters were adjusted using the experimental level energies tabulated by
Table 5. Oscillator strengths for transitions in Ra I.

\begin{tabular}{lrrrrrr}
\hline \hline$\lambda(\AA)^{a}$ & Int $^{a}$ & $E_{1}\left(\mathrm{~cm}^{-1}\right)$ & $J_{1}$ & $E_{\mathrm{u}}\left(\mathrm{cm}^{-1}\right)$ & $J_{\mathrm{u}}$ & $\log g f$ \\
\hline 4825.91 & 1000 & $0.00(e)$ & 0 & $20715.71(o)$ & 1 & 0.31 \\
5400.23 & 200 & $13993.97(e)$ & 2 & $32506.59(o)$ & 2 & -0.13 \\
5406.81 & 200 & $14707.35(e)$ & 3 & $33197.46(o)$ & 3 & 0.11 \\
5555.85 & 200 & $13999.38(o)$ & 1 & $31993.41(e)$ & 2 & 0.00 \\
5660.81 & 500 & $14707.35(e)$ & 3 & $32367.78(o)$ & 4 & 0.40 \\
6200.30 & 300 & $13993.97(e)$ & 2 & $30117.78(o)$ & 3 & 0.17 \\
6446.20 & 200 & $16688.54(o)$ & 2 & $32197.28(e)$ & 3 & 0.19 \\
6487.32 & 200 & $14707.35(e)$ & 3 & $30117.78(o)$ & 3 & -0.36 \\
6980.22 & 200 & $13715.85(e)$ & 1 & $28038.05(o)$ & 2 & -0.10 \\
7118.50 & 200 & $13993.97(e)$ & 2 & $28038.05(o)$ & 2 & -0.38 \\
7141.21 & 500 & $0.00(e)$ & 0 & $13999.38(o)$ & 1 & -1.08 \\
7225.16 & 200 & $17081.45(e)$ & 2 & $30918.14(o)$ & 2 & 0.20 \\
7838.12 & 200 & $13999.38(o)$ & 1 & $26754.05(e)$ & 1 & -0.16 \\
\hline
\end{tabular}

${ }^{a}$ From Sansonetti \& Martin (2005)

(see also http://physics.nist.gov/PhysRevData/Handbook/ Tables/radiumtable2.htm).

Table 6. Oscillator strengths for transitions in Ra II.

\begin{tabular}{lrrrrrr}
\hline \hline$\lambda(\AA)^{a}$ & $\operatorname{Int}^{a}$ & $E_{1}\left(\mathrm{~cm}^{-1}\right)$ & $J_{1}$ & $E_{\mathrm{u}}\left(\mathrm{cm}^{-1}\right)$ & $J_{\mathrm{u}}$ & $\log g f$ \\
\hline 2708.96 & 100 & $12084.38(e)$ & $3 / 2$ & $48987.98(o)$ & $5 / 2$ & 0.24 \\
2813.76 & 150 & $13743.11(e)$ & $5 / 2$ & $49272.31(o)$ & $7 / 2$ & 0.38 \\
3649.55 & 500 & $21351.20(o)$ & $1 / 2$ & $48744.04(e)$ & $3 / 2$ & 0.30 \\
3814.42 & 1000 & $0.00(e)$ & $1 / 2$ & $26208.86(o)$ & $3 / 2$ & 0.19 \\
4340.64 & 500 & $26208.86(o)$ & $3 / 2$ & $49240.48(e)$ & $5 / 2$ & 0.48 \\
4436.27 & 100 & $26208.86(o)$ & $3 / 2$ & $48744.04(e)$ & $3 / 2$ & -0.48 \\
4533.11 & 150 & $21351.20(o)$ & $1 / 2$ & $43405.01(e)$ & $1 / 2$ & -0.23 \\
4682.28 & 500 & $0.00(e)$ & $1 / 2$ & $21351.20(o)$ & $1 / 2$ & -0.20 \\
5813.63 & 100 & $26208.86(o)$ & $3 / 2$ & $43405.01(e)$ & $1 / 2$ & -0.04 \\
8019.70 & 250 & $13743.11(e)$ & $5 / 2$ & $26208.86(o)$ & $3 / 2$ & -0.12 \\
\hline
\end{tabular}

${ }^{a}$ From Sansonetti \& Martin (2005)

(see also http://physics.nist.gov/PhysRevData/Handbook/ Tables/radiumtable2.htm)

Blaise \& Wyart (1992). In addition, in order to reduce as much as possible the discrepancies between calculated and experimental energy levels, an effective interaction parameter $\alpha$ (Trees 1951a,b; Racah 1952) associated to the $6 \mathrm{~d}^{2}$ configuration was considered in the fitting process while the generalized Slater integrals $R^{k}$ corresponding to the configuration interactions between $6 \mathrm{~d} 7 \mathrm{p}$ and $7 \mathrm{~s} 5 \mathrm{f}$, on the one hand, and between $6 \mathrm{~d} 7 \mathrm{p}$ and $7 \mathrm{~s} 7 \mathrm{p}$, on the other hand, were also adjusted. It is worth noting that the new spectroscopic designations of some levels proposed by Blaise \& Wyart (1992) compared to the previous analysis due to Meggers et al. (1957) were confirmed in the present work. Although some levels belonging to $5 \mathrm{f} 7 \mathrm{p}$ are known experimentally, we preferred not to include those levels in the fitting procedure because, according to our calculations, they are situated in a region (from $\sim 55000$ to $\sim 65000 \mathrm{~cm}^{-1}$ ) where many levels of unknown configurations such as $7 \mathrm{p}^{2}, 6 \mathrm{~d} 8 \mathrm{~s}, 6 \mathrm{~d} 7 \mathrm{~d}$ and $7 \mathrm{~s} 7 \mathrm{~d}$ appear. The standard deviations were found to be equal to $179 \mathrm{~cm}^{-1}$ for the even parity (15 levels and 10 variable parameters) and $280 \mathrm{~cm}^{-1}$ for the odd parity (38 levels and 22 adjustable parameters).

The computed energies, Landé $g$-factors and eigenvector compositions as obtained in the present work for low-lying levels in Ra I, Ra II, Ac I and Ac II are reported in Tables 1-4 together with the available experimental data.

\section{Radiative rates and lifetimes}

Oscillator strengths obtained in the present work are reported in Tables 5-8 for selected transitions of RaI, RaII, 
Table 7. Oscillator strengths for transitions in Ac I.

\begin{tabular}{lrrrrrr}
\hline \hline$\lambda(\AA)^{a}$ & Int $^{a}$ & $E_{1}\left(\mathrm{~cm}^{-1}\right)$ & $J_{1}$ & $E_{\mathrm{u}}\left(\mathrm{cm}^{-1}\right)$ & $J_{\mathrm{u}}$ & $\log g f$ \\
\hline 3885.56 & 400 & $0.00(\mathrm{e})$ & $3 / 2$ & $25729.03(o)$ & $1 / 2$ & 0.15 \\
4034.63 & 200 & $2231.43(\mathrm{e})$ & $5 / 2$ & $27009.84(o)$ & $3 / 2$ & -0.15 \\
4063.10 & 200 & $2231.43(\mathrm{e})$ & $5 / 2$ & $26836.20(o)$ & $5 / 2$ & 0.51 \\
4179.98 & 1000 & $0.00(\mathrm{e})$ & $3 / 2$ & $23916.84(o)$ & $5 / 2$ & 0.14 \\
4183.12 & 500 & $0.00(\mathrm{e})$ & $3 / 2$ & $23898.86(o)$ & $5 / 2$ & -0.28 \\
4194.40 & 400 & $2231.43(\mathrm{e})$ & $5 / 2$ & $26066.04(o)$ & $3 / 2$ & -0.72 \\
4384.53 & 300 & $0.00(\mathrm{e})$ & $3 / 2$ & $22801.10(o)$ & $3 / 2$ & -1.46 \\
4396.71 & 400 & $2231.43(\mathrm{e})$ & $5 / 2$ & $24969.30(o)$ & $7 / 2$ & -1.82 \\
4462.73 & 400 & $0.00(\mathrm{e})$ & $3 / 2$ & $22401.52(o)$ & $1 / 2$ & -2.92 \\
4613.93 & 300 & $2231.43(\mathrm{e})$ & $5 / 2$ & $23898.86(o)$ & $5 / 2$ & -1.24 \\
4705.78 & 200 & $2231.43(\mathrm{e})$ & $5 / 2$ & $23475.94(o)$ & $7 / 2$ & -1.56 \\
4716.58 & 500 & $0.00(\mathrm{e})$ & $3 / 2$ & $21195.87(o)$ & $5 / 2$ & -1.37 \\
5258.24 & 300 & $0.00(\mathrm{e})$ & $3 / 2$ & $19012.46(o)$ & $3 / 2$ & -0.41 \\
5569.26 & 200 & $0.00(\mathrm{e})$ & $3 / 2$ & $17950.71(o)$ & $5 / 2$ & -1.29 \\
6359.86 & 300 & $2231.43(\mathrm{e})$ & $5 / 2$ & $17950.71(o)$ & $5 / 2$ & -0.98 \\
6691.27 & 200 & $0.00(\mathrm{e})$ & $3 / 2$ & $14940.72(o)$ & $5 / 2$ & -0.93 \\
7290.40 & 300 & $0.00(\mathrm{e})$ & $3 / 2$ & $13712.90(o)$ & $3 / 2$ & -1.18 \\
7866.10 & 200 & $2231.43(\mathrm{e})$ & $5 / 2$ & $14940.72(o)$ & $5 / 2$ & -1.24 \\
\hline
\end{tabular}

${ }^{a}$ From Sansonetti \& Martin (2005)

(see also http://physics.nist.gov/PhysRevData/

Handbook/Tables/actiniumtable2.htm) .

Ac I and Ac II, respectively. For most of these transitions, listed as strong lines by Sansonetti \& Martin (2005), radiative data are reported for the first time (see also http://physics.nist.gov/PhysRevData/Handbook/Tables/ radiumtable2.htm and http://physics.nist.gov/

PhysRevData/Handbook/Tables/actiniumtable2.htm).

For Ra I, a comparison between radiative lifetimes deduced from our calculations and available results is shown in Table 9. With the exception of the $6 \mathrm{~d} 7 \mathrm{~s}^{1} \mathrm{D}_{2}$ level $\left(E=17081.45 \mathrm{~cm}^{-1}\right)$, for which our computed transition probabilities are affected by large cancellation effects, a good agreement (5-20\%) is observed between the values calculated in the present work and the recent ones obtained by Dzuba \& Ginges (2006) using the many-body perturbation theory. For the $7 \mathrm{~s} 7 \mathrm{p}{ }^{3} \mathrm{P}_{1}^{\circ}$ level, our calculated lifetime $(\tau=281 \mathrm{~ns})$ is $\sim 30 \%$ shorter than the experimental measurement due to Scielzo et al. (2006). In order to see whether this difference could be due to an underestimation of core-polarization effects included in our theoretical model, we have performed semi-empirical HFR calculations including explicitly core-valence correlations by means of additional configurations with one hole in the $6 \mathrm{~s}$ or $6 \mathrm{p}$ subshell, instead of considering the core-polarization potential. More precisely, the following configurations were added to the ones considered in the physical model presented in Sect. 3.1.: $6 s^{2} 6 p^{5} 7 p^{3}+6 s^{2} 6 p^{5} 6 d^{2} 7 p+6 s^{2} 6 p^{5} 7 s^{2} 7 p$ $+6 s^{2} 6 p^{5} 6 d 7 s 7 p+6 s 6 p^{6} 6 d^{3}+6 s 6 p^{6} 6 d^{2} 7 s+6 s 6 p^{6} 6 d 7 s^{2}$ $+6 s 6 p^{6} 6 d^{2} p^{2}+6 s 6 p^{6} 7 s 7 p^{2}$ (even parity) and $6 s^{2} 6 p^{5} 6 d^{3}+$ $6 s^{2} 6 p^{5} 6 d^{2} 7 s+6 s^{2} 6 p^{5} 6 d 7 s^{2}+6 s^{2} 6 p^{5} 6 d 7 p^{2}+6 s^{2} 6 p^{5} 7 s 7 p^{2}+$ $6 s 6 p^{6} 7 p^{3}+6 s 6 p^{6} 6 d^{2} 7 p+6 s 6 p^{6} 7 s^{2} 7 p+6 s 6 p^{6} 6 d 7 s 7 p$ (odd parity). Using this model, the calculated lifetime for the $7 \mathrm{~s} 7 \mathrm{p}$ ${ }^{3} \mathrm{P}_{1}^{\circ}$ level was found to be equal to $250 \mathrm{~ns}$, i.e. $\sim 10 \%$ shorter than our HFR+CPOL calculation and $\sim 40 \%$ shorter than the measurement due to Scielzo et al. (2006). This indicates that core-polarization corrections were not underestimated in our HFR+CPOL model, having in mind that HFR calculations without core-polarization gave a lifetime value of $215 \mathrm{~ns}$. It was also verified that, for the levels at $13715.85,13999.38$, 16688.54, 17081.45 and $20715.71 \mathrm{~cm}^{-1}$, the magnetic
Table 8. Oscillator strengths for transitions in Ac II.

\begin{tabular}{lrrrrrr}
\hline \hline$\lambda(\AA)^{a}$ & $\mathrm{Int}^{a}$ & $E_{1}\left(\mathrm{~cm}^{-1}\right)$ & $J_{1}$ & $E_{\mathrm{u}}\left(\mathrm{cm}^{-1}\right)$ & $J_{\mathrm{u}}$ & $\log g f$ \\
\hline 2847.16 & 100 & $9087.54(e)$ & 2 & $44199.94(o)$ & 1 & -0.07 \\
2994.17 & 130 & $0.00(e)$ & 0 & $33388.61(o)$ & 1 & -0.21 \\
3043.30 & 300 & $9087.54(e)$ & 2 & $41937.05(o)$ & 3 & 0.19 \\
3069.36 & 130 & $13236.46(e)$ & 2 & $45807.06(o)$ & 3 & -0.17 \\
3112.83 & 130 & $4739.63(e)$ & 1 & $36855.50(o)$ & 1 & -0.31 \\
3153.09 & 300 & $5267.16(e)$ & 2 & $36972.94(o)$ & 3 & 0.29 \\
3154.41 & 300 & $7426.52(e)$ & 3 & $39119.02(o)$ & 4 & -0.93 \\
3164.81 & 150 & $5267.16(e)$ & 2 & $36855.50(o)$ & 1 & -0.13 \\
3230.59 & 130 & $7426.52(e)$ & 3 & $38371.64(o)$ & 2 & 0.10 \\
3260.91 & 300 & $4739.63(e)$ & 1 & $35397.12(o)$ & 2 & 0.14 \\
3383.53 & 130 & $7426.52(e)$ & 3 & $36972.94(o)$ & 3 & -1.17 \\
3413.84 & 130 & $9087.54(e)$ & 2 & $38371.64(o)$ & 2 & -0.24 \\
3417.77 & 200 & $0.00(e)$ & 0 & $29250.40(o)$ & 1 & -0.19 \\
3481.16 & 300 & $7426.52(e)$ & 3 & $36144.35(o)$ & 3 & 0.30 \\
3489.53 & 130 & $4739.63(e)$ & 1 & $33388.61(o)$ & 1 & -0.21 \\
3554.99 & 130 & $5267.16(e)$ & 2 & $33388.61(o)$ & 1 & -0.91 \\
3565.59 & 700 & $5267.16(e)$ & 2 & $33304.96(o)$ & 2 & -0.19 \\
3756.67 & 150 & $5267.16(e)$ & 2 & $31878.87(o)$ & 2 & -0.23 \\
3799.82 & 70 & $9087.54(e)$ & 2 & $35397.12(o)$ & 2 & -0.76 \\
3863.12 & 700 & $7426.52(e)$ & 3 & $33304.96(o)$ & 2 & -0.08 \\
4061.60 & 150 & $5267.16(e)$ & 2 & $29881.09(o)$ & 3 & -0.47 \\
4088.44 & 1000 & $7426.52(e)$ & 3 & $31878.87(o)$ & 2 & -1.02 \\
4168.40 & 700 & $5267.16(e)$ & 2 & $29250.40(o)$ & 1 & -0.46 \\
4209.69 & 100 & $7426.52(e)$ & 3 & $31174.60(o)$ & 3 & -0.49 \\
4359.13 & 130 & $5267.16(e)$ & 2 & $28201.11(o)$ & 2 & -0.44 \\
4386.41 & 500 & $9087.54(e)$ & 2 & $31878.87(o)$ & 2 & 0.08 \\
4507.20 & 700 & $0.00(e)$ & 0 & $22180.52(o)$ & 1 & -1.04 \\
4605.45 & 300 & $4739.63(e)$ & 1 & $26446.96(o)$ & 2 & -1.66 \\
4720.16 & 300 & $5267.16(e)$ & 2 & $26446.96(o)$ & 2 & -1.14 \\
4812.22 & 200 & $7426.52(e)$ & 3 & $28201.11(o)$ & 2 & $-3.07 *$ \\
5732.05 & 70 & $4739.63(e)$ & 1 & $22180.52(o)$ & 1 & -0.93 \\
5758.97 & 130 & $9087.54(e)$ & 2 & $26446.96(o)$ & 2 & -1.37 \\
5910.85 & 300 & $5267.16(e)$ & 2 & $22180.52(o)$ & 1 & -0.60 \\
6164.75 & 200 & $4739.63(e)$ & 1 & $20956.40(o)$ & 0 & -0.85 \\
6167.83 & 30 & $16756.90(e)$ & 4 & $32965.55(o)$ & 4 & -0.50 \\
6242.83 & 100 & $13236.46(e)$ & 2 & $29250.40(o)$ & 1 & -0.58 \\
\hline & & & & \\
& & &
\end{tabular}

${ }^{a}$ From Sansonetti \& Martin (2005)

(see also http://physics.nist.gov/PhysRevData/ Handbook/Tables/actiniumtable2.htm).

${ }^{*}$ Affected by severe cancellation effects.

dipole (M1) and electric quadrupole (E2) contributions were negligible.

For Ra II, a comparison between our oscillator strengths and previous results was already presented in our recent paper related to Fr-like ions (Biémont et al. 2004). In that paper, we pointed out that our multiplet $f$-values were $25 \%$ lower than the results obtained for the 7s-7p transition by Sen \& Puri (1989b) using the quasi-relativistic local spin density functional approach. However, the results obtained in our work were considered to be more reliable than those published by Sen \& Puri in view of the excellent agreement observed between the accurate lifetimes measured by Zhao et al. (1997) and Simsarian et al. (1998) for the levels $7 p_{1 / 2}$ and $7 p_{3 / 2}$ in the isoelectronic francium atom and our calculations performed using exactly the same model as the one used for Ra II (Biémont et al. 1998). It was also shown in Biémont et al. (2004) that our results were in reasonable agreement with those of Lindgård \& Nielsen (1977), Glushkov (1991) and Glushkov et al. (1996), using the Coulomb approximation and a model potential method, respectively, for the $7 \mathrm{~s}-7 \mathrm{p}, 7 \mathrm{p}-8 \mathrm{~s}, 8 \mathrm{~s}-8 \mathrm{p}, 6 \mathrm{~d}-7 \mathrm{p}, 7 \mathrm{p}-7 \mathrm{~d}$ and $7 \mathrm{~d}-8 \mathrm{p}$ transition arrays in singly ionized radium. Very recently, the $7 \mathrm{~s}-7 \mathrm{p}$ electric dipole 
Table 9. Comparison of lifetimes of low-lying states of Ra I.

\begin{tabular}{|c|c|c|c|c|c|c|c|c|c|}
\hline Level & $E\left(\mathrm{~cm}^{-1}\right)$ & Type & This work & $\mathrm{MBPT}^{a}$ & $\mathrm{MCDHF}^{b}$ & $\mathrm{RHF}^{c}$ & $\mathrm{MCDF}^{d}$ & $\mathrm{RPP}^{e}$ & $\operatorname{EXP}^{f}$ \\
\hline $6 \mathrm{~d} 7 \mathrm{~s}^{3} \mathrm{D}_{1}$ & 13715.85 & E1 & $694 \mu \mathrm{s}$ & $654 \mu \mathrm{s}$ & & $617 \mu \mathrm{s}$ & & & \\
\hline $6 \mathrm{~d} 7 \mathrm{~s}^{3} \mathrm{D}_{2}$ & 13993.97 & E2 & $3.0 \mathrm{~s}$ & $3.3 \mathrm{~s}$ & $4 \mathrm{~s}$ & $15 \mathrm{~s}$ & & & \\
\hline $7 \mathrm{~s} 7 \mathrm{p}{ }^{3} \mathrm{P}_{1}{ }^{\circ}$ & 13999.38 & E1 & $281 \mathrm{~ns}$ & $362 \mathrm{~ns}$ & & $505 \mathrm{~ns}$ & $250 \mathrm{~ns}$ & $420 \mathrm{~ns}$ & $422(20) \mathrm{ns}$ \\
\hline $7 \mathrm{~s} 7 \mathrm{p}^{3} \mathrm{P}_{2}{ }^{\circ}$ & 16688.54 & E1 & $6.4 \mu \mathrm{s}$ & $5.55 \mu \mathrm{s}$ & & $5.2 \mu \mathrm{s}$ & & & \\
\hline $6 \mathrm{~d} 7 \mathrm{~s}{ }^{1} \mathrm{D}_{2}$ & 17081.45 & E1 & $-*$ & $129 \mu \mathrm{s}$ & & $38 \mathrm{~ms}$ & & & \\
\hline $7 \mathrm{~s} 7 \mathrm{p}^{1} \mathrm{P}_{1}{ }^{\circ}$ & 20715.71 & E1 & $5.2 \mathrm{~ns}$ & $5.53 \mathrm{~ns}$ & & $5.5 \mathrm{~ns}$ & & & \\
\hline
\end{tabular}

${ }^{a}$ Many-body perturbation theory (Dzuba \& Ginges 2006). ${ }^{b}$ Multiconfiguration Dirac-Hartree-Fock (Bieron et al. 2004). ${ }^{c}$ Relativistic HartreeFock (Dzuba et al. 2000). ${ }^{d}$ Multiconfiguration Dirac-Fock (Bruneau 1984). ${ }^{e}$ Relativistic pseudo-potential (Hafner \& Schwarz 1978). ${ }^{f}$ Experiment (Scielzo et al. 2006). * Affected by severe cancellation effects.

and $7 \mathrm{~s}-6 \mathrm{~d}$ electric quadrupole matrix elements in $\mathrm{Ra}^{+}$were evaluated by Safronova (2007) using a relativistic coupled-cluster method in which single, double and partial triple excitations of Dirac-Fock wavefunctions were included to all orders of perturbation theory. The theoretical lifetimes taken from this study for $7 \mathrm{p}_{1 / 2}(\tau=8.94 \mathrm{~ns}), 7 \mathrm{p}_{3 / 2}(\tau=4.84 \mathrm{~ns}), 6 \mathrm{~d}_{3 / 2}(\tau=0.669 \mathrm{~s})$ and $6 \mathrm{~d}_{5 / 2}(\tau=0.334 \mathrm{~s})$ are in excellent agreement (within a few percents) with the values deduced from the present work, i.e. $\tau=9.48 \mathrm{~ns}, 4.97 \mathrm{~ns}, 0.611 \mathrm{~s}$ and $0.316 \mathrm{~s}$, respectively.

In the case of actinium, the only available result for comparison is the one published by Sen \& Puri (1989a) for the $7 \mathrm{~s}^{2}{ }^{1} \mathrm{~S}_{0}-$ $7 \mathrm{~s} 7 \mathrm{p}{ }^{1} \mathrm{P}_{1}^{\circ}$ transition in Ac II. The oscillator strength computed by these authors $(\log g f=0.45)$ is considerably larger than the result obtained in the present work $(\log g f=-0.21)$. This is probably due to the fact that the quite simple model used by Sen \& Puri (1989a) underestimated the strong mixing between the 7s7p ${ }^{1} \mathrm{P}_{1}^{\circ}$ and $6 \mathrm{~d} 7 \mathrm{p}^{3} \mathrm{D}_{1}^{\circ}$ states. In fact, for the level at $33388.61 \mathrm{~cm}^{-1}$, classified as $7 \mathrm{~s} 7 \mathrm{p}^{1} \mathrm{P}_{1}^{\circ}$ in the NIST tables (Moore 1971), our calculations gave a mixing of $61 \% 6 \mathrm{~d} 7 \mathrm{p}^{3} \mathrm{D}_{1}^{\circ}+23 \% 7 \mathrm{~s} 7 \mathrm{p}{ }^{1} \mathrm{P}_{1}^{\circ}$, in very good agreement with the composition $(60 \%+28 \%)$ obtained by Blaise \& Wyart (1992) using the parametric SlaterCondon method. Moreover, it is interesting to note that, when performing a very simple HFR calculation, including only $7 \mathrm{~s}^{2}$ and $7 \mathrm{~s} 7 \mathrm{p}$ configurations, we could obtain an oscillator strength $(\log g f=0.40)$ in good agreement with the one published by Sen \& Puri (1989a).

\section{Partition functions}

The calculation of ionization equilibrium in stellar atmospheres using Saha equation requires the evaluation of the partition functions for neutral and ionized species. The values computed in the present work for radium and actinium are given in Table 10 for temperatures from 3000 to $14000 \mathrm{~K}$. These results were obtained, for each element, using the available experimental levels completed with all the calculated values deduced from the theoretical models described in Sect. 3. This corresponds to total numbers of levels equal to 539, 78, 1722 and 539 for Ra I, Ra II, Ac I and Ac II, respectively. In order to estimate the detrimental effect of missing experimental levels on the partition functions, the latter were also computed using only the available experimental energies. When doing so, it was found that the partition functions reported in Table 10 were almost unaffected for $T=3000 \mathrm{~K}$ while they were decreased by a factor of $2.06,1.04$, 2.73 and 1.06 for $T=14000 \mathrm{~K}$ in the case of Ra I, Ra II, Ac I and Ac II, respectively.

\section{Astrophysical applications}

As pointed out by Cowley et al. (2004), Gopka et al. (2004) and Bidelman (2005), the lines of radioactive elements can be
Table 10. Partition functions in Ra I, Ra II, Ac I and Ac II.

\begin{tabular}{rrrrr}
\hline \hline$T(\mathrm{~K})$ & Ra I & Ra II & Ac I & Ac II \\
\hline 3000 & 1.03 & 2.02 & 6.31 & 1.99 \\
3500 & 1.07 & 2.05 & 6.96 & 2.50 \\
4000 & 1.15 & 2.10 & 7.72 & 3.09 \\
4500 & 1.26 & 2.16 & 8.64 & 3.73 \\
5000 & 1.43 & 2.25 & 9.73 & 4.42 \\
5500 & 1.66 & 2.35 & 11.01 & 5.16 \\
6000 & 1.95 & 2.46 & 12.50 & 5.94 \\
6500 & 2.31 & 2.59 & 14.21 & 6.75 \\
7000 & 2.76 & 2.73 & 16.16 & 7.60 \\
7500 & 3.30 & 2.89 & 18.37 & 8.49 \\
8000 & 3.97 & 3.05 & 20.86 & 9.42 \\
8500 & 4.76 & 3.22 & 23.67 & 10.38 \\
9000 & 5.70 & 3.39 & 26.81 & 11.39 \\
9500 & 6.81 & 3.57 & 30.32 & 12.44 \\
10000 & 8.10 & 3.77 & 34.22 & 13.53 \\
10500 & 9.58 & 3.96 & 38.54 & 14.67 \\
11000 & 11.26 & 4.17 & 43.31 & 15.87 \\
11500 & 13.17 & 4.38 & 48.54 & 17.12 \\
12000 & 15.30 & 4.61 & 54.28 & 18.42 \\
12500 & 17.67 & 4.84 & 60.52 & 19.79 \\
13000 & 20.29 & 5.09 & 67.29 & 21.22 \\
13500 & 23.15 & 5.36 & 74.62 & 22.73 \\
14000 & 26.26 & 5.63 & 82.51 & 24.30 \\
\hline
\end{tabular}

identified in the spectra of Przybylski's star (HD 101065) and of HR 465. Yushchenko et al. (2007) tried to estimate the abundances of actinides, forcing all oscillator strengths to zero. Using the new atomic data obtained in the present work for radium and actinium, we investigated the astrophysical spectra of these two stars.

Some of the wavelengths reported in Tables 5-8 being shorter than $3000 \AA$, we first used observed IUE spectra from INES archive, namely LWR06999HL for the Przybylski's star and LWP14571HL, LWP14572HL, LWR03984HS, LWR03987HS, LWR07217HL, LWR14522HL, LWR14526HL for HR 465. The spectral resolution $(R)$ of IUE spectra is about $0.1 \AA$ while the signal to noise ratio $(S / N)$ is in the range extending from 10 up to 30 . Observed spectrum of Przybylski's star at longer wavelengths (from 3040 to $10350 \AA$ A) was taken from VLT archives (Bagnulo et al. 2002). This spectrum is characterized by a resolution of 80000 and a $S / N$ ratio greater than 300 . For HR 465 , we used two spectra for wavelengths longer than $3000 \AA$. The first one $(\lambda=$ 4000-6800 $, R=40000, S / N=70-100)$, registered in 1996 with the 1.93 meter telescope of Haute-Provence Observatory (France), was extracted from the archives of this observatory 

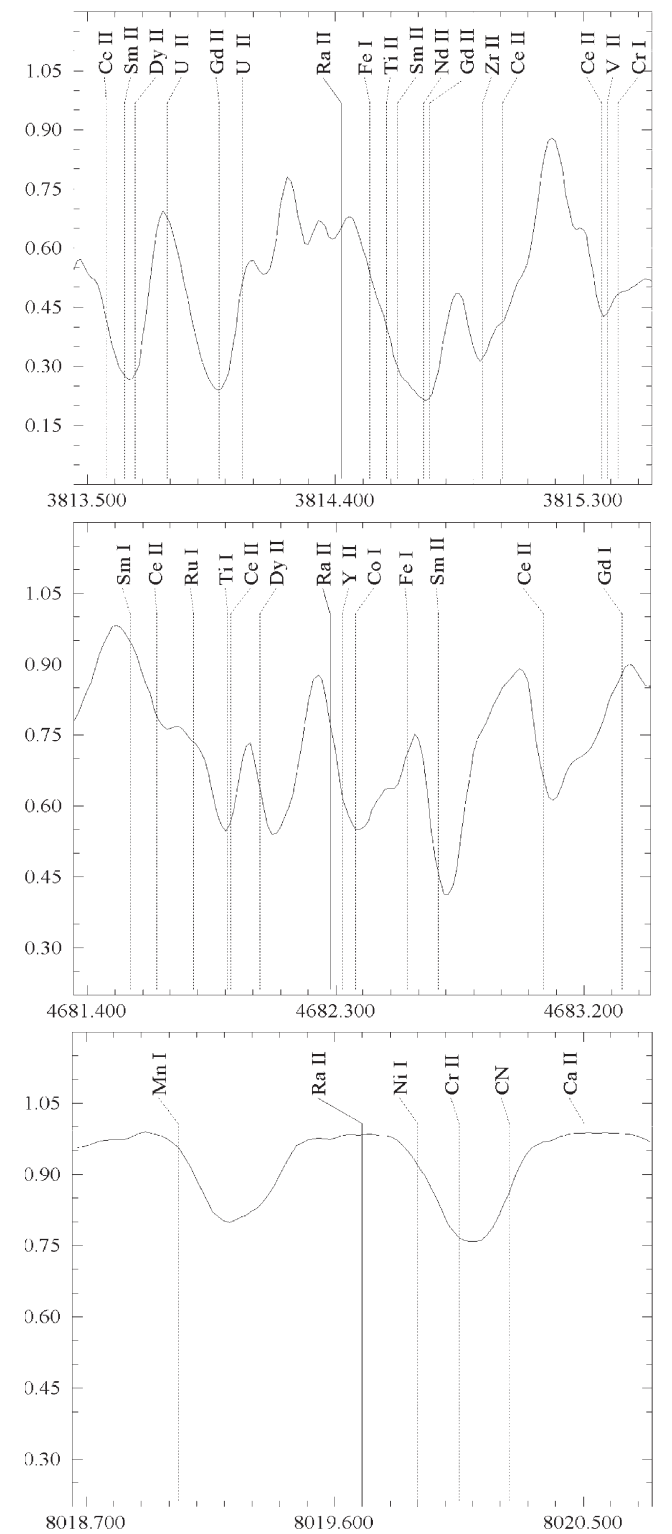

Fig. 1. Three Ra II lines in the spectrum of Przybylski's star. Tentative identifications have also been performed for neighbouring lines but they are very uncertain in some cases. The $x$ - and $y$-axis correspond to wavelengths (in $\AA$ ) and intensities (in arbitrary units), respectively.

(Prugniel \& Soubiran 2001). The second spectrum $(\lambda=3780-$ $9500 \AA, R=80000, S / N>100)$ was observed in 2004 with the $1.8 \mathrm{~m}$ telescope of Bohuynsan Observatory (Korea). It should be mentioned that, due to the strong variability of spectral lines in HR 465 with a period of 22-24 years (Preston \& Wolff 1970), the first spectrum shows enhanced chromium lines while the second one shows enhanced lanthanide lines.

Both HD 101065 and HR 465 stars have very complicated spectra with a significant part of spectral lines being unidentified. Yushchenko et al. (2007) showed that strong stratification of chemical elements could exist in the atmosphere of Przybylski's star but, unfortunately, there is presently no accurate atmospheric model susceptible to describe the observed spectrum of this star correctly. Consequently, we restrict ourselves, in the present paper, to a short discussion of possible identifications of some lines of radium and actinium in the spectra of these two stars.
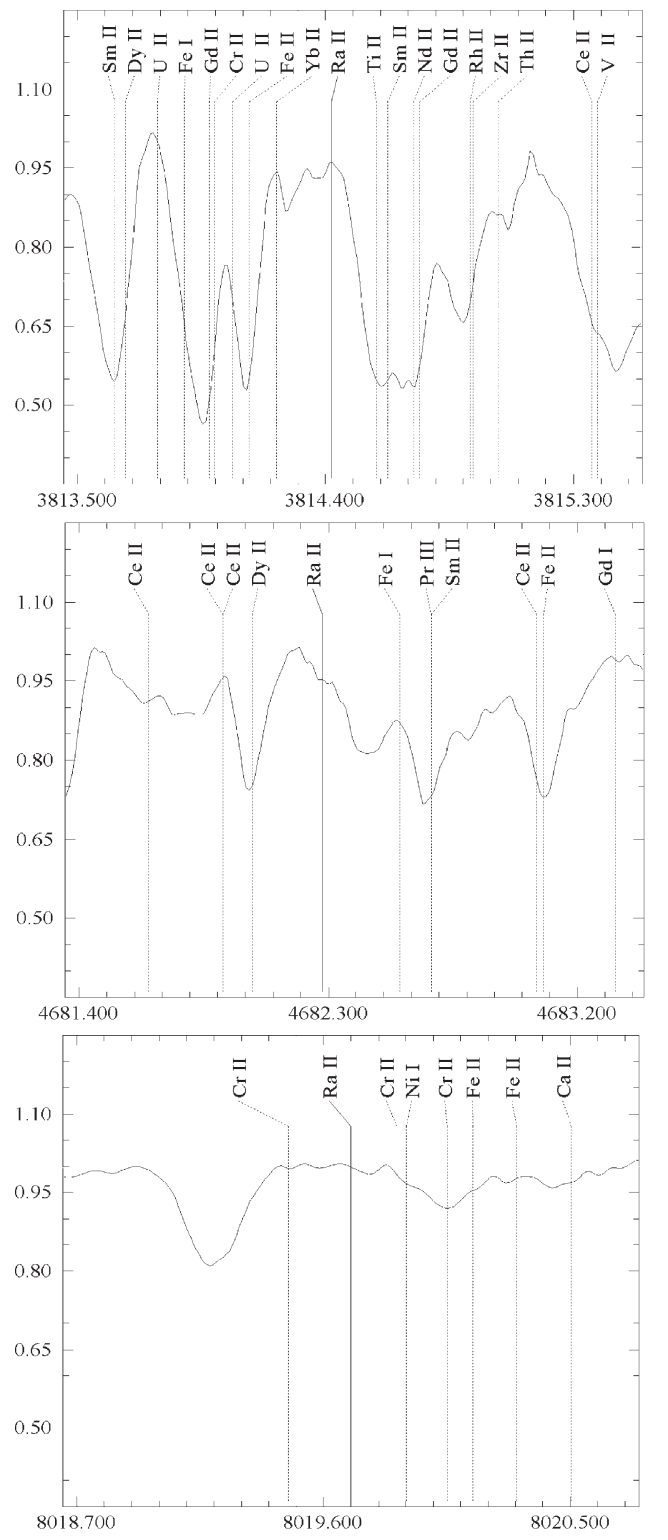

Fig. 2. Same as Fig. 1 for the HR 465 star.

\subsection{Radium lines}

The $\mathrm{Ra}$ II line at $2708.96 \AA$ is in the blue wing of the strong $\lambda 2709.056 \mathrm{Fe}$ II line and the influence of the strong $\lambda 2708.957$ Ce II line can explain the observations of Przybylski's star spectrum. The line at $2813.76 \AA$ is faint and located in crowded spectral region. The strongest contribution of the absorption feature at this wavelength in the spectrum of Pzrybylski's star is due to the Os I line at $2813.762 \AA$. Ultraviolet spectra show numerous absorption lines but the $S / N$ ratio of IUE spectra being only about $10-30$, it is very difficult to express any definitive conclusion about possible presence of radium lines in this spectral region. In the visible region, the two $\mathrm{Ra}$ II lines at 3649.55 and $4340.64 \AA$ are very close to $\mathrm{H}$ I Balmer lines $\mathrm{H}_{62}(3649.543 \AA)$ and $\mathrm{H}_{\gamma}(4340.462 \AA)$. The lines at 4436.27, 4533.11 and $5813.63 \AA$ are too faint to be detected or are contaminated by lines of other elements.

In fact only three Ra II lines could be used to estimate the upper limit of radium abundance in the atmospheres of the 

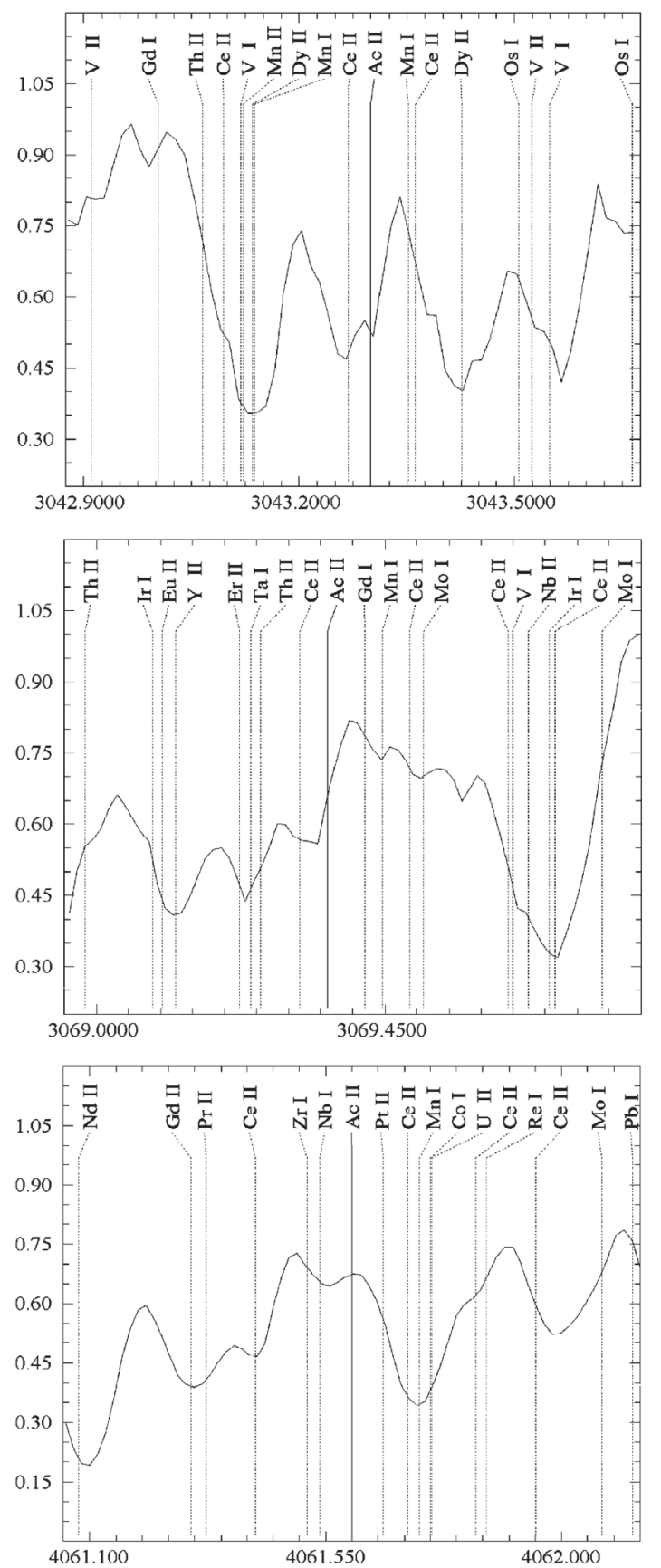
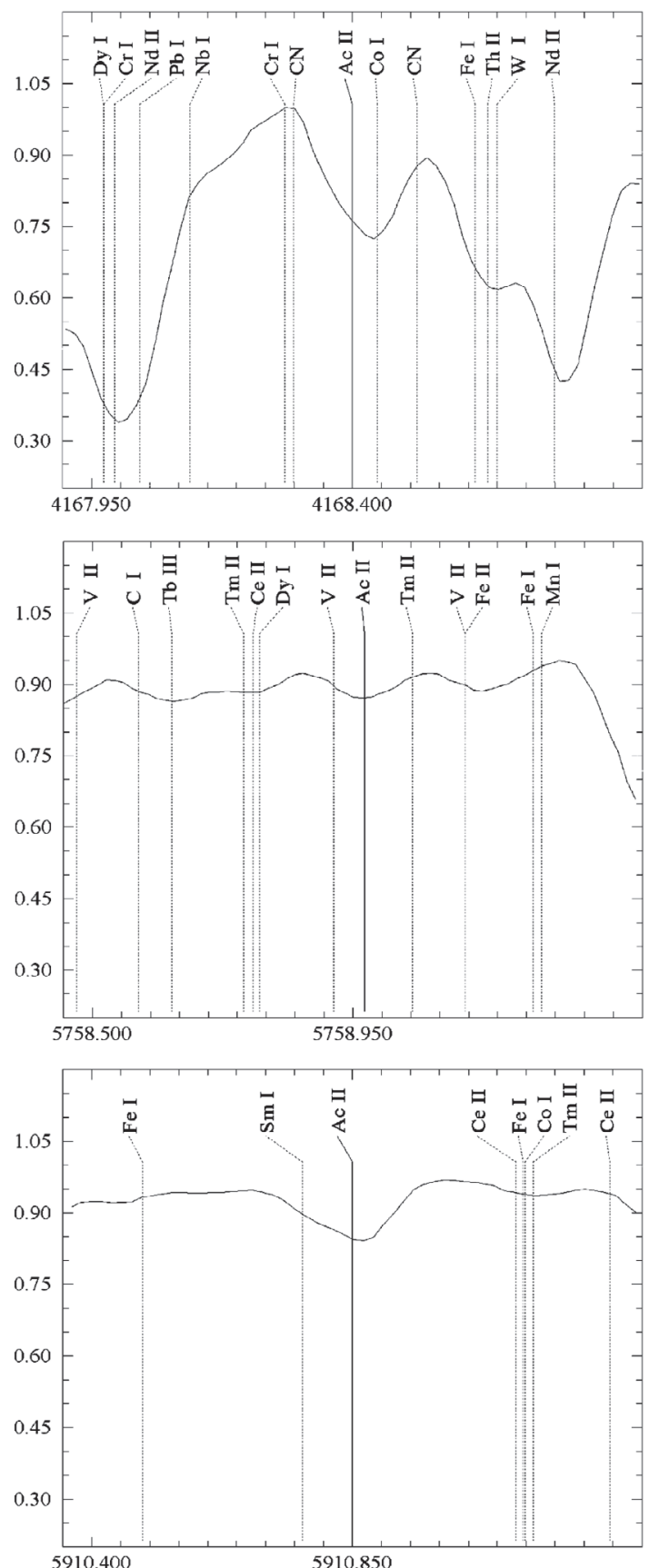

Fig. 3. The six spectral regions around possible Ac II lines in the spectrum of Pzrybylski's star. The $x$ - and $y$-axis correspond to wavelengths (in $\AA$ ) and intensities (in arbitrary units), respectively.

investigated stars if dedicated stellar models were available. These lines, located at $3814.42,4682.28$ and $8019.70 \AA$, are shown in Figs. 1 and 2 for HD 101065 and HR 465 stars, respectively. For the first line $(\lambda=3814.42 \AA)$, the observed wavelength is $3814.40 \AA$ in Przybylski's star and $3814.39 \AA$ in HR 465. This line is free of strong blending. For the line at 4682.28 $\AA$, we found no counterparts in the observed spectra. The Y II line at $4682.324 \AA$ is the strongest blending line in the spectra of both stars while the Os I line at $4682.06 \AA$ should influence the spectrum of Przybylski's star only. Ra II line at $8019.70 \AA$ is too weak and could not be identified. The spectral region around this wavelength could be used for determining an upper limit to the stellar content of radium.

\subsection{Actinium lines}

The search for actinium lines in the HR 465 spectrum was not successful. For most of the lines, the appearance of the observed spectrum can be explained by lines of other elements. In contrast, actinium lines could possibly be present in the spectrum of Przybylski's star. Figure 3 shows the observed spectra of HD 101065 and identifications of the strongest lines. For the Ac II line at $3043.30 \AA$, the observed wavelength is $3043.01 \AA$. Some blends could be due to Ce II (ג3043.268) and Tb III ( $\lambda 3043.324)$ lines but the influence of these lines is not expected to be important. For the line at $3069.36 \AA$, the observed wavelength at $3069.345 \AA$ is free from strong blending but the $\mathrm{Ce}$ II line at $3069.318 \AA$ should however be taken into account. 
The Ac II line at $4061.60 \AA$, observed at $4061.556 \AA$ in the HD 101065 spectrum, could be blended with $\mathrm{Nb}$ I ( $\lambda$ 4061.539) and $\mathrm{Zr}$ I ( $\lambda 4061.515)$ lines. The line at $4168.40 \AA$, observed at $4168.436 \AA$, is one of the best lines for which actinium can make the largest input to the absorption feature, the lines of other elements being weak except the Co I contribution at $\lambda 4068.443$. Finally, the Ac II lines at 5758.97 and $5910.85 \AA$ (observed at 5758.97 and $5910.865 \AA$ ) are not expected to be affected by strong blends and the identification of these lines as due to actinium is plausible according to the available linelists.

\section{Conclusion}

Oscillator strengths have been calculated for strong lines in neutral and singly ionized radium (Ra I-II) and actinium (Ac I-II). For most of the transitions considered in the present work, $f$-values are reported for the first time. These new results are intended to provide astrophysicists with some of the data they need for quantitative investigations of stellar spectra where such radiaoactive elements are expected to be observed. The two cases of HD 101065 and HR 465 are considered. A close examination of the spectra indicates that some absorption features observed in the spectra of these stars could possibly be due to Ra II and Ac II. A more quantitative analysis however is awaiting the availability of accurate models describing the atmospheres of these stars.

Acknowledgements. P.Q. and E.B. are respectively Research Associate and Research Director of the Belgian Fund for Scientific Research (F.N.R.S.). V.F. has a fellowship of the F.R.I.A. Financial support from these organizations is acknowledged. A.Y. was supported by the Astrophysical Research Center for the Structure and Evolution of the Cosmos (ARCSEC) of the Korea Science and Engineering Foundation (KOSEF) through the Science Research Center (SRC) program. We thank Dr. M.S. Safronova for sending us some results in advance of publication.

\section{References}

Bagnulo, S., Jehin, E., Ledoux, C., et al. 2002, A Library of HighResolution Spectra of Stars accross the Hertzsprung-Russel Diagram, http://www.sc.eso.org/santiago/uvespop/index.html

Bidelman, W. P. 2005, in Cosmic Abundances as Records of Stellar Evolution and Nucleosynthesis, ed. T. G. Barnes III, \& F. N. Bash, ASP Conf. Ser., 336, 309

Biémont, É., Quinet, P., \& Van Renterghem V. 1998, J. Phys. B, 31, 5301

Biémont, É., Fivet, V., \& Quinet, P. 2004, J. Phys. B, 37, 4193

Bieron, J., Froese Fischer, C., Fritzche, S., \& Pachucki, K. 2004, J. Phys. B, 37, L305

Blaise, J., \& Wyart J.-F. 1992, Selected Constants, Energy Levels and Atomic Spectra of Actinides,

http://www.lac.u-psud.fr/Database/Contents.html
Bruneau, J. 1984, J. Phys. B, 17, 3009

Cowan, R. D. 1981, The Theory of Atomic Structure and Spectra (Berkeley: University of California Press)

Cowley, C. R., \& Hartoog, M. R. 1972, ApJ, 178, L9

Cowley, C. R., Ryabchikova, T. R., Kupla, F., et al. 2000, MNRAS, 317, 299

Cowley, C. R. 2003, http://astro.1sa.umich.edu/users/cowley/

Cowley, C. R., Bidelman, W. P., Hubrig, S., Mathys, G., \& Bord, D. J. 2004, A\&A, 419, 1087

Dzuba, V. A., \& Ginges, J. S. M. 2006, Phys. Rev. A, 73, 032503

Dzuba, V. A., Flambaum, V. V., \& Ginges, J. S. M. 2000, Phys. Rev. A 61, 062509

Fraga, S., Karwowski, J., \& Saxena, K. M. S. 1976, Handbook of Atomic Data (Amsterdam: Elsevier)

Fred, M., Tomkins, F. S., \& Meggers, W. F. 1955, Phys. Rev., 98, 1514

Glushkov, A. V. 1991, Opt. Spectrosc. (USSR), 70, 555

Glushkov, A. V. Butenko, Yu. V., Serbov, N. G., et al. 1996, J. Appl. Spectrosc., 63,28

Gopka, V. F., Yushchenko, A. V., Shavrina, A. V., et al. 2004, The A-Star Puzzle, Proc. IAU Symp. 224, ed. J. Zverko, J. Ziznovsky, S. J. Adelman, \& W. W. Weiss

Gopka, V. F., Yushchenko, A. V., Goriely, S., Shavrina, A. V., \& Kang, Y. W. 2006, Int. Symp. on Origin of Matter and Evolution of Galaxies: New Horizon of Nuclear Astrophysics and Cosmology, AIP Conf. Proc. 847, 389 Goriely, S. 2007, A\&A, 466, 619

Goriely, S., \& Arnould, M. 2001, A\&A, 379, 1113

Hafner, P., \& Schwarz, W. H. E. 1978, J. Phys. B, 11, 2975

Lindgård, A., \& Nielsen, S. E. 1977, At. Data Nucl. Data Tables, 19, 533

Meggers, W. F., Fred, M., \& Tomkins, F. S. 1957, J. Res. Nat. Bur. Stand. (USA), 58, 297

Merrill, P. W. 1952, ApJ, 116, 21

Moore, C. E. 1971, Atomic Energy Levels, NSRDS-NBS 35, Vol. III

Preston, C. W., \& Wolff, S. C. 1970, ApJ, 160, 1071

Prugniell, Ph., \& Soubiran, C. 2001, A\&A, 369, 1048

Przybylski, A. 1961, Nature, 189, 739

Quinet, P., Palmeri, P., Biémont, É., et al. 1999, MNRAS, 307, 934

Racah, G. 1952, Phys. Rev., 85, 381

Rasmussen, E. 1933, Z. Phys., 86, 24

Rasmussen, E. 1934a, Z. Phys., 87, 607

Rasmussen, E. 1934b, Z. Phys., 87, 615

Russel, H. N. 1934, Phys. Rev., 46, 989

Safronova, M. S. 2007, private communication

Sansonetti, J. E., \& Martin, W. C. 2005, Handbook of Basic Atomic Spectroscopic Data, http://physics.nist.gov/PhysRefData/Handbook/index.html

Scielzo, N. D., Guest, J. R., Schulte, E. C., et al. 2006, Phys. Rev. A, 73, 010501

Sen, K. D., \& Puri, A. 1989a, Chem. Phys. Lett. 156, 505

Sen, K. D., \& Puri, A. 1989b, Phys. Lett. A, 137, 128

Simsarian, J. E., Orozco, L. A., Sprouse, G. D., \& Zhao, W. Z., 1998, Phys. Rev. A, 57, 2448

Trees, R. E. 1951a, Phys. Rev., 83, 756

Trees, R. E. 1951b, Phys. Rev., 84, 1089

Yushchenko, A., Gopka, V., Goriely, S., et al. 2006, Int. Symp. on Nuclear Astrophysics - Nuclei in the Cosmos - IX, CERN, Geneva, Switzerland

Yushchenko, A., Gopka, V., Goriely, S., et al. 2007, [arXiv: astro-ph/0610611]

Zhao, W. Z., Simsarian, J. E., Orozco, L. A., \& Sprouse, G. D. 1997, Phys. Rev. Lett., 78, 4169 
P. Quinet et al.: Atomic data for Ra I, Ra II, Ac I and Ac II, Online Material $p 1$

\section{Online Material}


P. Quinet et al.: Atomic data for Ra I, Ra II, Ac I and Ac II, Online Material p 2

Table 1. Comparison between experimental and calculated energy levels in Ra I.

\begin{tabular}{|c|c|c|c|c|c|c|}
\hline Designation $^{a}$ & $J$ & $\begin{array}{r}E_{\exp }^{a} \\
\left(\mathrm{~cm}^{-1}\right)\end{array}$ & $\begin{array}{c}E_{\text {calc }}^{b} \\
\left(\mathrm{~cm}^{-1}\right)\end{array}$ & $\begin{array}{r}\Delta E^{c} \\
\left(\mathrm{~cm}^{-1}\right)\end{array}$ & $g^{d}$ & Composition $^{e}$ \\
\hline \multicolumn{7}{|l|}{ Even parity } \\
\hline $7 \mathrm{~s}^{2}{ }^{1} \mathrm{~S}$ & 0 & 0.00 & 0 & 0 & & $96 \% 7 \mathrm{~s}^{2}{ }^{1} \mathrm{~S}$ \\
\hline $6 \mathrm{~d} 7 \mathrm{~s}{ }^{3} \mathrm{D}$ & 1 & 13715.85 & 13695 & 21 & 0.499 & $100 \% 6 \mathrm{~d} 7 \mathrm{~s}^{3} \mathrm{D}$ \\
\hline $6 \mathrm{~d} 7 \mathrm{~s}{ }^{3} \mathrm{D}$ & 2 & 13993.97 & 14022 & -28 & 1.163 & $97 \% 6 \mathrm{~d} 7 \mathrm{~s}^{3} \mathrm{D}$ \\
\hline $6 \mathrm{~d} 7 \mathrm{~s}{ }^{3} \mathrm{D}$ & 3 & 14707.35 & 14701 & 6 & 1.334 & $100 \% 6 \mathrm{~d} 7 \mathrm{~s}^{3} \mathrm{D}$ \\
\hline $6 \mathrm{~d} 7 \mathrm{~s}{ }^{1} \mathrm{D}$ & 2 & 17081.45 & 17080 & 1 & 1.004 & $88 \% 6 \mathrm{~d} 7 \mathrm{~s}{ }^{1} \mathrm{D}+5 \% 7 \mathrm{p}^{2}{ }^{1} \mathrm{D}$ \\
\hline \multirow[t]{6}{*}{$7 \mathrm{~s} 8 \mathrm{~s}^{3} \mathrm{~S}$} & 1 & 26754.05 & 26754 & 0 & 2.002 & $100 \% 7 \mathrm{~s} 8 \mathrm{~s}^{3} S$ \\
\hline & 0 & & 27714 & & & $83 \% 7 \mathrm{~s} 8 \mathrm{~s}{ }^{1} \mathrm{~S}+6 \% 6 \mathrm{~d}^{2}{ }^{1} \mathrm{~S}$ \\
\hline & 2 & & 29476 & & 0.765 & $74 \% 6 \mathrm{~d}^{2}{ }^{3} \mathrm{~F}+16 \% 6 \mathrm{~d}^{21} \mathrm{D}$ \\
\hline & 0 & & 29778 & & & $42 \% 6 \mathrm{~d}^{2}{ }^{3} \mathrm{P}+36 \% 7 \mathrm{p}^{2}{ }^{3} \mathrm{P}+11 \% 7 \mathrm{~s} 8 \mathrm{~s}{ }^{1} \mathrm{~S}$ \\
\hline & 3 & & 30832 & & 1.084 & $99 \% 6 d^{2}{ }^{3} F$ \\
\hline & 2 & & 30893 & & 1.046 & $24 \% 6 d^{2}{ }^{1} \mathrm{D}+22 \% 6 \mathrm{~d}^{2}{ }^{3} \mathrm{~F}+16 \% 6 \mathrm{~d}^{2}{ }^{3} \mathrm{P}$ \\
\hline \multirow[t]{2}{*}{$7 p^{23} \mathrm{P}$} & 1 & 31248.61 & 31035 & 214 & 1.501 & $61 \% 6 d^{2}{ }^{3} \mathrm{P}+39 \% 7 \mathrm{p}^{2}{ }^{3} \mathrm{P}$ \\
\hline & 4 & & 31915 & & 1.238 & $95 \% 6 d^{2}{ }^{3} F$ \\
\hline $7 \mathrm{~s} 7 \mathrm{~d}^{3} \mathrm{D}$ & 2 & 31993.41 & 31935 & 59 & 1.184 & $44 \% 7 \mathrm{~s} 7 \mathrm{~d}^{1} \mathrm{D}+20 \% 6 \mathrm{~d}^{2}{ }^{3} \mathrm{P}+19 \% 7 \mathrm{~s} 7 \mathrm{~d}^{3} \mathrm{D}$ \\
\hline $7 \mathrm{~s} 7 \mathrm{~d}^{3} \mathrm{D}$ & 1 & 32000.82 & 32042 & -41 & 0.499 & $95 \% 7 \mathrm{~s} 7 \mathrm{~d}^{3} \mathrm{D}$ \\
\hline $7 \mathrm{~s} 7 \mathrm{~d}^{3} \mathrm{D}$ & 3 & 32197.28 & 32216 & -19 & 1.334 & $97 \% 7 \mathrm{~s} 7 \mathrm{~d}^{3} \mathrm{D}$ \\
\hline $7 \mathrm{p}^{2}{ }^{1} \mathrm{D}$ & 2 & 32214.84 & 32154 & 61 & 1.177 & $76 \% 7 \mathrm{~s} 7 \mathrm{~d}^{3} \mathrm{D}+11 \% 7 \mathrm{~s} 7 \mathrm{~d}^{1} \mathrm{D}+6 \% 6 \mathrm{~d}^{2}{ }^{3} \mathrm{P}$ \\
\hline \multirow[t]{2}{*}{$7 \mathrm{p}^{2}{ }^{3} \mathrm{P}$} & 2 & 32941.13 & 33180 & -239 & 1.163 & $34 \% 6 d^{2}{ }^{1} \mathrm{D}+24 \% 6 \mathrm{~d}^{2}{ }^{3} \mathrm{P}+14 \% 7 \mathrm{~s} 7 \mathrm{~d}^{1} \mathrm{D}$ \\
\hline & 0 & & 34041 & & & $47 \% 7 \mathrm{~s} 9 \mathrm{~s}^{1} \mathrm{~S}+24 \% 6 \mathrm{~d}^{2}{ }^{1} \mathrm{~S}+15 \% 7 \mathrm{p}^{2}{ }^{1} \mathrm{~S}$ \\
\hline \multirow[t]{3}{*}{$7 \mathrm{~s} 9 \mathrm{~s}{ }^{3} \mathrm{~S}$} & 1 & 34475.78 & 34476 & 0 & 2.002 & $100 \% 7 \mathrm{~s} 9 s^{3} \mathrm{~S}$ \\
\hline & 4 & & 34741 & & 1.012 & $92 \% 6 \mathrm{~d}^{2}{ }^{1} \mathrm{G}$ \\
\hline & 0 & & 35775 & & & $51 \% 7 \mathrm{~s} 9 \mathrm{~s}^{1} \mathrm{~S}+21 \% 6 \mathrm{~d}^{2}{ }^{1} \mathrm{~S}+12 \% 7 \mathrm{p}^{2}{ }^{1} \mathrm{~S}$ \\
\hline \multicolumn{7}{|c|}{ Odd parity } \\
\hline $7 \mathrm{~s} 7 \mathrm{p}^{3} \mathrm{P}^{\circ}$ & 0 & 13078.44 & 13145 & -67 & & $99 \% 7 \mathrm{~s} 7 \mathrm{p}^{3} \mathrm{P}^{\circ}$ \\
\hline $7 \mathrm{~s} 7 \mathrm{p}^{3} \mathrm{P}^{\circ}$ & 1 & 13999.38 & 13924 & 75 & 1.472 & $93 \% 7 \mathrm{~s} 7 \mathrm{p}^{3} \mathrm{P}^{\circ}$ \\
\hline $7 \mathrm{~s} 7 \mathrm{p}^{3} \mathrm{P}^{\circ}$ & 2 & 16688.54 & 16691 & -3 & 1.501 & $98 \% 7 \mathrm{~s} 7 \mathrm{p}^{3} \mathrm{P}^{\circ}$ \\
\hline $7 \mathrm{~s} 7 \mathrm{p}^{1} \mathrm{P}^{\circ}$ & 1 & 20715.71 & 20732 & -16 & 1.028 & $78 \% 7 \mathrm{~s} 7 \mathrm{p}{ }^{1} \mathrm{P}^{\circ}+14 \% 6 \mathrm{~d} 7 \mathrm{p}{ }^{1} \mathrm{P}^{\circ}+6 \% 7 \mathrm{~s} 7 \mathrm{p}^{3} \mathrm{P}^{\circ}$ \\
\hline $6 d 7 p^{3} F^{\circ}$ & 2 & 28038.05 & 28276 & -238 & 0.739 & $78 \% 6 \mathrm{~d} 7 \mathrm{p}^{3} \mathrm{~F}^{\circ}+19 \% 6 \mathrm{~d} 7 \mathrm{p}^{1} \mathrm{D}^{\circ}$ \\
\hline $6 \mathrm{~d} 7 \mathrm{p}^{3} \mathrm{~F}^{\circ}$ & 3 & 30117.78 & 30175 & -57 & 1.089 & $95 \% 6 \mathrm{~d} 7 \mathrm{p}^{3} \mathrm{~F}^{\circ}$ \\
\hline $6 \mathrm{~d} 7 \mathrm{p}^{1} \mathrm{D}^{\circ}$ & 2 & 30918.14 & 30862 & 56 & 1.025 & $65 \% 6 \mathrm{~d} 7 \mathrm{p}^{1} \mathrm{D}^{\circ}+17 \% 6 \mathrm{~d} 7 \mathrm{p}^{3} \mathrm{~F}^{\circ}+13 \% 6 \mathrm{~d} 7 \mathrm{p}^{3} \mathrm{P}^{\circ}$ \\
\hline $7 \mathrm{~s} 8 \mathrm{p}^{3} \mathrm{P}^{\circ}$ & 0 & 31085.88 & 31452 & -366 & & $90 \% 7 \mathrm{~s} 7 \mathrm{p}^{3} \mathrm{P}^{\circ}+9 \% 6 \mathrm{~d} 7 \mathrm{p}^{3} \mathrm{P}^{\circ}$ \\
\hline $7 \mathrm{~s} 8 \mathrm{p}^{3} \mathrm{P}^{\circ}$ & 1 & 31563.29 & 31071 & 493 & 0.969 & $41 \% 6 \mathrm{~d} 7 \mathrm{p}{ }^{3} \mathrm{D}^{\circ}+20 \% 7 \mathrm{~s} 8 \mathrm{p}^{3} \mathrm{P}^{\circ}+14 \% 6 \mathrm{~d} 7 \mathrm{p}{ }^{3} \mathrm{P}^{\circ}$ \\
\hline $7 \mathrm{~s} 8 \mathrm{p}^{3} \mathrm{P}^{\circ}$ & 2 & 31874.44 & 31958 & -84 & 1.436 & $79 \% 7 \mathrm{~s} 8 \mathrm{p}^{3} \mathrm{P}^{\circ}+7 \% 6 \mathrm{~d} 7 \mathrm{p}^{1} \mathrm{D}^{\circ}+6 \% 6 \mathrm{~d} 7 \mathrm{p}^{3} \mathrm{P}^{\circ}$ \\
\hline $6 \mathrm{~d} 7 \mathrm{p}^{3} \mathrm{D}^{\circ}$ & 1 & 32229.97 & 31774 & 456 & 1.212 & $69 \% 7 \mathrm{~s} 8 \mathrm{p}^{3} \mathrm{P}^{\circ}+28 \% 6 \mathrm{~d} 7 \mathrm{p}^{3} \mathrm{D}^{\circ}$ \\
\hline $6 \mathrm{~d} 7 \mathrm{p}^{3} \mathrm{~F}^{\circ}$ & 4 & 32367.78 & 32138 & 230 & 1.251 & $96 \% 6 \mathrm{~d} 7 \mathrm{p}^{3} \mathrm{~F}^{\circ}$ \\
\hline $6 \mathrm{~d} 7 \mathrm{p}^{3} \mathrm{D}^{\circ}$ & 2 & 32506.59 & 32619 & -112 & 1.214 & $81 \% 6 \mathrm{~d} 7 \mathrm{p}^{3} \mathrm{D}^{\circ}+11 \% 7 \mathrm{~s} 8 \mathrm{p}^{3} \mathrm{P}^{\circ}+6 \% 6 \mathrm{~d} 7 \mathrm{p}^{3} \mathrm{P}^{\circ}$ \\
\hline $7 \mathrm{~s} 8 \mathrm{p}^{1} \mathrm{P}^{\circ}$ & 1 & 32857.68 & 32954 & -96 & 0.903 & $58 \% 7 \mathrm{~s} 8 \mathrm{p}^{1} \mathrm{P}^{\circ}+24 \% 6 \mathrm{~d} 7 \mathrm{p}^{3} \mathrm{D}^{\circ}+10 \% 6 \mathrm{~d} 7 \mathrm{p}^{1} \mathrm{P}^{\circ}$ \\
\hline $6 \mathrm{~d} 7 \mathrm{p}^{3} \mathrm{D}^{\circ}$ & 3 & 33197.46 & 33452 & -254 & 1.204 & $60 \% 6 \mathrm{~d} 7 \mathrm{p}^{3} \mathrm{D}^{\circ}+22 \% 6 \mathrm{~d} 7 \mathrm{p}^{1} \mathrm{~F}^{\circ}+13 \% 7 \mathrm{~s} 5 \mathrm{f}^{1} \mathrm{~F}^{\circ}$ \\
\hline $6 \mathrm{~d} 7 \mathrm{p}^{3} \mathrm{P}^{\circ}$ & 0 & 33782.41 & 33731 & 52 & & $86 \% 6 \mathrm{~d} 7 \mathrm{p}{ }^{3} \mathrm{P}^{\circ}+9 \% 7 \mathrm{~s} 8 \mathrm{p}{ }^{3} \mathrm{P}^{\circ}$ \\
\hline $6 \mathrm{~d} 7 \mathrm{p}^{3} \mathrm{P}^{\circ}$ & 1 & 33823.70 & 33865 & -41 & 1.407 & $75 \% 6 \mathrm{~d} 7 \mathrm{p}^{3} \mathrm{P}^{\circ}+9 \% 7 \mathrm{~s} 8 \mathrm{p}^{1} \mathrm{P}^{\circ}+7 \% 7 \mathrm{~s} 8 \mathrm{p}^{3} \mathrm{P}^{\circ}$ \\
\hline \multirow[t]{2}{*}{$6 \mathrm{~d} 7 \mathrm{p}^{3} \mathrm{P}^{\circ}$} & 2 & 34382.91 & 34439 & -56 & 1.423 & $69 \% 6 \mathrm{~d} 7 \mathrm{p}^{3} \mathrm{P}^{\circ}+12 \% 6 \mathrm{~d} 7 \mathrm{p}^{3} \mathrm{D}^{\circ}+8 \% 6 \mathrm{~d} 7 \mathrm{p}^{1} \mathrm{D}^{\circ}$ \\
\hline & 3 & & 34551 & & 1.110 & $50 \% 7 \mathrm{~s} 5 \mathrm{f}^{1} \mathrm{~F}^{\circ}+32 \% 6 \mathrm{~d} 7 \mathrm{p}^{3} \mathrm{D}^{\circ}+14 \% 6 \mathrm{~d} 7 \mathrm{p}^{1} \mathrm{~F}^{\circ}$ \\
\hline $7 \mathrm{~s} 5 \mathrm{f}^{3} \mathrm{~F}^{\circ}$ & 2 & 35255.65 & 35232 & 23 & 0.666 & $98 \% 7 \mathrm{~s} 5 \mathrm{f}^{3} \mathrm{~F}^{\circ}$ \\
\hline $7 \mathrm{~s} 5 \mathrm{f}^{3} \mathrm{~F}^{\circ}$ & 3 & 35268.02 & 35257 & 11 & 1.084 & $98 \% 7 \mathrm{~s} 5 \mathrm{f}^{3} \mathrm{~F}^{\circ}$ \\
\hline \multirow[t]{7}{*}{$7 \mathrm{~s} 5 \mathrm{f}^{3} \mathrm{~F}^{\circ}$} & 4 & 35294.40 & 35299 & -5 & 1.251 & $97 \% 7 \mathrm{~s} 5 \mathrm{f}^{3} \mathrm{~F}^{\circ}$ \\
\hline & 1 & & 35631 & & 1.063 & $77 \% 7 \mathrm{~s} 9 \mathrm{p}^{1} \mathrm{P}^{\circ}+9 \% 7 \mathrm{~s} 9 \mathrm{p}^{3} \mathrm{P}^{\circ}$ \\
\hline & 0 & & 35748 & & & $97 \% 7 \mathrm{~s} 9 \mathrm{p}^{3} \mathrm{P}^{\circ}$ \\
\hline & 1 & & 35850 & & 1.445 & $88 \% 7 \mathrm{~s} 9 \mathrm{p}{ }^{3} \mathrm{P}^{\circ}+9 \% 7 \mathrm{~s} 9 \mathrm{p}^{1} \mathrm{P}^{\circ}$ \\
\hline & 2 & & 36006 & & 1.500 & $96 \% 7 \mathrm{~s} 9 \mathrm{p}^{3} \mathrm{P}^{\circ}$ \\
\hline & 3 & & 36685 & & 1.012 & $34 \% 7 \mathrm{~s} 5 \mathrm{f}^{1} \mathrm{~F}^{\circ}+32 \% 6 \mathrm{~d} 7 \mathrm{p}{ }^{1} \mathrm{~F}^{\circ}+22 \% 7 \mathrm{~s} 6 \mathrm{f}^{1} \mathrm{~F}^{\circ}$ \\
\hline & 2 & & 37906 & & 0.666 & $99 \% 7 \mathrm{~s} 6 \mathrm{f}^{3} \mathrm{~F}^{\circ}$ \\
\hline $7 \mathrm{~s} 6 \mathrm{f}^{3} \mathrm{~F}^{\circ}$ & 3 & 37922.26 & 37917 & 5 & 1.084 & $99 \% 7 \mathrm{~s} 6 \mathrm{f}^{3} \mathrm{~F}^{\circ}$ \\
\hline \multirow[t]{3}{*}{$7 \mathrm{~s} 6 \mathrm{f}^{3} \mathrm{~F}^{\circ}$} & 4 & 37929.64 & 37932 & -2 & 1.251 & $99 \% 7 \mathrm{~s} 6 \mathrm{f}^{3} \mathrm{~F}^{\circ}$ \\
\hline & 3 & & 38386 & & 1.002 & $72 \% 7 \mathrm{~s} 6 \mathrm{f}^{1} \mathrm{~F}^{\circ}+13 \% 6 \mathrm{~d} 7 \mathrm{p}^{1} \mathrm{~F}^{\circ}+7 \% 7 \mathrm{~s} 7 \mathrm{f}^{1} \mathrm{~F}^{\circ}$ \\
\hline & 2 & & 39353 & & 0.666 & $99 \% 7 \mathrm{~s} 7 \mathrm{f}^{3} \mathrm{~F}^{\circ}$ \\
\hline $7 \mathrm{~s} 7 \mathrm{f}^{3} \mathrm{~F}^{\circ}$ & 3 & 39360.96 & 39360 & 1 & 1.084 & $99 \% 7 \mathrm{~s} 7 \mathrm{f}^{3} \mathrm{~F}^{\circ}$ \\
\hline $7 \mathrm{~s} 7 \mathrm{f}^{3} \mathrm{~F}^{\circ}$ & 4 & 39366.98 & 39367 & 0 & 1.251 & $99 \% 7 \mathrm{~s} 7 \mathrm{f}^{3} \mathrm{~F}^{\circ}$ \\
\hline
\end{tabular}


P. Quinet et al.: Atomic data for Ra I, Ra II, Ac I and Ac II, Online Material $p 3$

Table 1. continued.

\begin{tabular}{|c|c|c|c|c|c|c|}
\hline Designation $^{a}$ & $J$ & $\begin{array}{r}E_{\exp }^{a} \\
\left(\mathrm{~cm}^{-1}\right)\end{array}$ & $\begin{array}{r}E_{\text {calc }}^{b} \\
\left(\mathrm{~cm}^{-1}\right)\end{array}$ & $\begin{array}{r}\Delta E^{c} \\
\left(\mathrm{~cm}^{-1}\right)\end{array}$ & $g^{d}$ & Composition $^{e}$ \\
\hline & 1 & & 39540 & & 1.003 & $43 \% 6 \mathrm{~d} 7 \mathrm{p}^{1} \mathrm{P}^{\circ}+21 \% 6 \mathrm{~d} 8 \mathrm{p}{ }^{1} \mathrm{P}^{\circ}+9 \% 7 \mathrm{~s} 9 \mathrm{p}^{1} \mathrm{P}^{\circ}$ \\
\hline & 3 & & 39546 & & 1.001 & $86 \% 7 \mathrm{~s} 7 \mathrm{f}^{1} \mathrm{~F}^{\circ}$ \\
\hline $7 \mathrm{~s} 8 \mathrm{f}^{3} \mathrm{~F}^{\circ}$ & 2 & 40219.50 & 40217 & 2 & 0.666 & $90 \% 7 \mathrm{~s} 8 \mathrm{f}^{3} \mathrm{~F}^{\circ}+8 \% 7 \mathrm{~s} 9 \mathrm{f}^{3} \mathrm{~F}^{\circ}$ \\
\hline $7 \mathrm{~s} 8 \mathrm{f}^{3} \mathrm{~F}^{\circ}$ & 3 & 40219.50 & 40223 & -4 & 1.083 & $92 \% 7 \mathrm{~s} 8 \mathrm{f}^{3} \mathrm{~F}^{\circ}+7 \% 7 \mathrm{~s} 9 \mathrm{f}^{3} \mathrm{~F}^{\circ}$ \\
\hline \multirow[t]{2}{*}{$7 \mathrm{~s} 8 \mathrm{f}^{3} \mathrm{~F}^{\circ}$} & 4 & 40231.58 & 40229 & 2 & 1.251 & $94 \% 7 \mathrm{~s} 8 \mathrm{f}^{3} \mathrm{~F}^{\circ}+5 \% 7 \mathrm{~s} 9 \mathrm{f}^{3} \mathrm{~F}^{\circ}$ \\
\hline & 3 & & 40280 & & 1.000 & $64 \% 7 \mathrm{~s} 8 \mathrm{f}^{1} \mathrm{~F}^{\circ}+36 \% 7 \mathrm{~s} 9 \mathrm{f}^{1} \mathrm{~F}^{\circ}$ \\
\hline
\end{tabular}

${ }^{a}$ From Moore (1971). ${ }^{b}$ Semi-empirical HFR calculations (present work). ${ }^{c} \Delta E=E_{\text {exp }}-E_{\text {calc }}{ }^{d}$ Landé factor as calculated in the present work. ${ }^{e}$ Only the first three components $\geq 5 \%$ are given. See Sect. 3.1 for explanations concerning the differences between the designations from Moore (1971) and the calculated compositions. 
P. Quinet et al.: Atomic data for Ra I, Ra II, Ac I and Ac II, Online Material p 4

Table 2. Experimental energy levels and calculated Landé $g$-factors in Ra II. For this ion, the differences $\Delta E=E_{\text {exp }}-E_{\text {calc }}=0 \mathrm{~cm}^{-1}$ and the eigenvector purities are equal to $100 \%$ for all the levels (see the text).

\begin{tabular}{|c|c|c|c|}
\hline Designation $^{a}$ & $J$ & $\begin{array}{r}E_{\exp }^{a} \\
\left(\mathrm{~cm}^{-1}\right)\end{array}$ & $g^{b}$ \\
\hline \multicolumn{4}{|l|}{ Even parity } \\
\hline$\overline{7 s^{2} S}$ & $1 / 2$ & 0.00 & 2.002 \\
\hline $6 d^{2} D$ & $3 / 2$ & 12084.38 & 0.800 \\
\hline $6 d^{2} D$ & $5 / 2$ & 13743.11 & 1.200 \\
\hline $8 s^{2} S$ & $1 / 2$ & 43405.01 & 2.002 \\
\hline $7 d^{2} D$ & $3 / 2$ & 48744.04 & 0.800 \\
\hline $7 d^{2} D$ & $5 / 2$ & 49240.48 & 1.200 \\
\hline $9{ }^{2} S$ & $1 / 2$ & 59165.23 & 2.002 \\
\hline $8 d^{2} D$ & $3 / 2$ & 61734.88 & 0.800 \\
\hline $8 d^{2} D$ & $5 / 2$ & 61973.82 & 1.200 \\
\hline $5 g^{2} G$ & $7 / 2$ & 64150.65 & 0.889 \\
\hline $5 g^{2} \mathrm{G}$ & $9 / 2$ & 64150.65 & 1.111 \\
\hline $10 \mathrm{~s}^{2} \mathrm{~S}$ & $1 / 2$ & 66837.88 & 2.002 \\
\hline $9 d^{2} D$ & $3 / 2$ & 68264.07 & 0.800 \\
\hline $9 d^{2} D$ & $5 / 2$ & 68394.86 & 1.200 \\
\hline $6 g^{2} G$ & $7 / 2$ & 69560.85 & 0.889 \\
\hline $6 g^{2} \mathrm{G}$ & $9 / 2$ & 69560.85 & 1.111 \\
\hline $11 \mathrm{~s}^{2} \mathrm{~S}$ & $1 / 2$ & 71172.92 & 2.002 \\
\hline $10 \mathrm{~d}^{2} \mathrm{D}$ & $3 / 2$ & 72043.06 & 0.800 \\
\hline $10 \mathrm{~d}^{2} \mathrm{D}$ & $5 / 2$ & 72123.78 & 1.200 \\
\hline $7 \mathrm{~g}^{2} \mathrm{G}$ & $7 / 2$ & 72824.37 & 0.889 \\
\hline $7 g^{2} G$ & $9 / 2$ & 72824.37 & 1.111 \\
\hline $12 \mathrm{~s}^{2} \mathrm{~S}$ & $1 / 2$ & 73863.1 & 2.002 \\
\hline $11 d^{2} D$ & $3 / 2$ & 74434.04 & 0.800 \\
\hline $11 d^{2} D$ & $5 / 2$ & 74488.51 & 1.200 \\
\hline $8 \mathrm{~g}^{2} \mathrm{G}$ & $7 / 2$ & 74941.91 & 0.889 \\
\hline $8 \mathrm{~g}^{2} \mathrm{G}$ & $9 / 2$ & 74941.91 & 1.111 \\
\hline $12 \mathrm{~d}^{2} \mathrm{D}$ & $3 / 2$ & [76047] & 0.800 \\
\hline $12 d^{2} D$ & $5 / 2$ & 76080.74 & 1.200 \\
\hline $9 g^{2} G$ & $7 / 2$ & 76393.12 & 0.889 \\
\hline $9 g^{2} \mathrm{G}$ & $9 / 2$ & 76393.12 & 1.111 \\
\hline $10 \mathrm{~g}^{2} \mathrm{G}$ & $7 / 2$ & 77431.31 & 0.889 \\
\hline $10 \mathrm{~g}^{2} \mathrm{G}$ & $9 / 2$ & 77431.31 & 1.111 \\
\hline $11 \mathrm{~g}^{2} \mathrm{G}$ & $7 / 2$ & 78195.21 & 0.889 \\
\hline $11 \mathrm{~g}^{2} \mathrm{G}$ & $9 / 2$ & 78195.21 & 1.111 \\
\hline \multicolumn{4}{|l|}{ Odd parity } \\
\hline$\overline{7 p^{2} \mathrm{P}^{\circ}}$ & $1 / 2$ & 21351.20 & 0.666 \\
\hline $7 \mathrm{p}^{2} \mathrm{P}^{\circ}$ & $3 / 2$ & 26208.86 & 1.334 \\
\hline $5 f^{2} \mathrm{~F}^{\circ}$ & $5 / 2$ & 48987.98 & 0.857 \\
\hline $5 f^{2} \mathrm{~F}^{\circ}$ & $7 / 2$ & 49272.31 & 1.143 \\
\hline $8 \mathrm{p}^{2} \mathrm{P}^{\circ}$ & $1 / 2$ & 50606.01 & 0.666 \\
\hline $8 \mathrm{p}^{2} \mathrm{P}^{\circ}$ & $3 / 2$ & 52392.05 & 1.334 \\
\hline $6 f^{2} \mathrm{~F}^{\circ}$ & $5 / 2$ & 59515.48 & 0.857 \\
\hline $6 f^{2} \mathrm{~F}^{\circ}$ & $7 / 2$ & 59815.59 & 1.143 \\
\hline $9 \mathrm{p}^{2} \mathrm{P}^{\circ}$ & $1 / 2$ & [62 977] & 0.666 \\
\hline $9 \mathrm{p}^{2} \mathrm{P}^{\circ}$ & $3 / 2$ & 63410.41 & 1.334 \\
\hline $7 f^{2} \mathrm{~F}^{\circ}$ & $5 / 2$ & 66521.86 & 0.857 \\
\hline $7 f^{2} F^{\circ}$ & $7 / 2$ & 66691.22 & 1.143 \\
\hline
\end{tabular}

${ }^{a}$ From Moore (1971). Energies between brackets are calculated values obtained in the present work. ${ }^{b}$ Landé factor as calculated in the present work. 
P. Quinet et al.: Atomic data for Ra I, Ra II, Ac I and Ac II, Online Material p 5

Table 3. Comparison between experimental and calculated energy levels in Ac I.

\begin{tabular}{|c|c|c|c|c|c|c|}
\hline Designation $^{a}$ & $J$ & $\begin{array}{r}E_{\exp }^{a} \\
\left(\mathrm{~cm}^{-1}\right)\end{array}$ & $\begin{array}{c}E_{\text {calc }}^{b} \\
\left(\mathrm{~cm}^{-1}\right)\end{array}$ & $\begin{array}{r}\Delta E^{c} \\
\left(\mathrm{~cm}^{-1}\right)\end{array}$ & $g^{d}$ & Composition $^{e}$ \\
\hline \multicolumn{7}{|l|}{ Even parity } \\
\hline $6 \mathrm{~d} 7 \mathrm{~s}^{2}{ }^{2} \mathrm{D}$ & $3 / 2$ & 0.00 & 0 & 0 & 0.799 & $90 \% 6 \mathrm{~d} 7 \mathrm{~s}^{2}{ }^{2} \mathrm{D}$ \\
\hline $6 \mathrm{~d} 7 \mathrm{~s}^{2}{ }^{2} \mathrm{D}$ & $5 / 2$ & 2231.43 & 2231 & 0 & 1.200 & $89 \% 6 \mathrm{~d} 7 \mathrm{~s}^{2}{ }^{2} \mathrm{D}+5 \% 6 \mathrm{~d}^{2}\left({ }^{1} \mathrm{D}\right) 7 \mathrm{~s}^{2} \mathrm{D}$ \\
\hline $6 d^{2}\left({ }^{3} F\right) 7 s{ }^{4} F$ & $3 / 2$ & 9217.28 & 9204 & 13 & 1.679 & $95 \% 6 d^{2}\left({ }^{3} F\right) 7 s^{4} F$ \\
\hline $6 d^{2}\left({ }^{3} F\right) 7 s{ }^{4} F$ & $5 / 2$ & 9863.59 & 9879 & -15 & 1.031 & $94 \% 6 d^{2}\left({ }^{3} \mathrm{~F}\right) 7 \mathrm{~s}{ }^{4} \mathrm{~F}$ \\
\hline $6 d^{2}\left({ }^{3} F\right) 7 s{ }^{4} F$ & $7 / 2$ & 10906.02 & 10910 & -4 & 1.237 & $97 \% 6 d^{2}\left({ }^{3} F\right) 7 s^{4} F$ \\
\hline $6 d^{2}\left({ }^{3} F\right) 7 s{ }^{4} F$ & $9 / 2$ & 12078.07 & 12072 & 6 & 1.329 & $97 \% 6 d^{2}\left({ }^{3} F\right) 7 s^{4} F$ \\
\hline \multicolumn{7}{|l|}{ Odd parity } \\
\hline & $1 / 2$ & & 9465 & & 0.663 & $84 \% 7 \mathrm{~s}^{2} 7 \mathrm{p}^{2} \mathrm{P}^{\circ}+10 \% 6 \mathrm{~d} 7 \mathrm{~s}\left({ }^{3} \mathrm{D}\right) 7 \mathrm{p}{ }^{2} \mathrm{P}^{\circ}$ \\
\hline & $3 / 2$ & & 13173 & & 1.334 & $78 \% 7 \mathrm{~s}^{2} 7 \mathrm{p}^{2} \mathrm{P}^{\circ}+12 \% 6 \mathrm{~d} 7 \mathrm{~s}\left({ }^{3} \mathrm{D}\right) 7 \mathrm{p}^{2} \mathrm{P}^{\circ}$ \\
\hline $6 \mathrm{~d} 7 \mathrm{~s}\left({ }^{3} \mathrm{D}\right) 7 \mathrm{p}{ }^{4} \mathrm{~F}^{\circ}$ & $3 / 2$ & 13712.90 & 15193 & -1480 & 0.465 & $84 \% 6 \mathrm{~d} 7 \mathrm{~s}\left({ }^{3} \mathrm{D}\right) 7 \mathrm{p}{ }^{4} \mathrm{~F}^{\circ}+8 \% 6 \mathrm{~d} 7 \mathrm{~s}\left({ }^{3} \mathrm{D}\right) 7 \mathrm{p}^{2} \mathrm{D}^{\circ}$ \\
\hline $6 \mathrm{~d} 7 \mathrm{~s}\left({ }^{3} \mathrm{D}\right) 7 \mathrm{p}{ }^{4} \mathrm{~F}^{\circ}$ & $5 / 2$ & 14940.72 & 16290 & -1349 & 1.071 & $70 \% 6 \mathrm{~d} 7 \mathrm{~s}\left({ }^{3} \mathrm{D}\right) 7 \mathrm{p}{ }^{4} \mathrm{~F}^{\circ}+10 \% 6 \mathrm{~d} 7 \mathrm{~s}\left({ }^{3} \mathrm{D}\right) 7 \mathrm{p}{ }^{2} \mathrm{D}^{\circ}+8 \% 6 \mathrm{~d} 7 \mathrm{~s}\left({ }^{1} \mathrm{D}\right) 7 \mathrm{p}{ }^{2} \mathrm{D}^{\circ}$ \\
\hline $6 \mathrm{~d} 7 \mathrm{~s}\left({ }^{3} \mathrm{D}\right) 7 \mathrm{p}{ }^{4} \mathrm{D}^{\circ}$ & $1 / 2$ & 17199.71 & 17561 & -361 & 0.058 & $93 \% 6 \mathrm{~d} 7 \mathrm{~s}\left({ }^{3} \mathrm{D}\right) 7 \mathrm{p}{ }^{4} \mathrm{D}^{\circ}$ \\
\hline $6 \mathrm{~d} 7 \mathrm{~s}\left({ }^{3} \mathrm{D}\right) 7 \mathrm{p}{ }^{4} \mathrm{~F}^{\circ}$ & $7 / 2$ & 17683.87 & 18852 & -1168 & 1.239 & $94 \% 6 \mathrm{~d} 7 \mathrm{~s}\left({ }^{3} \mathrm{D}\right) 7 \mathrm{p}{ }^{4} \mathrm{~F}^{\circ}$ \\
\hline $6 \mathrm{~d} 7 \mathrm{~s}\left({ }^{3} \mathrm{D}\right) 7 \mathrm{p}^{2} \mathrm{D}^{\circ}$ & $3 / 2$ & 17736.26 & 18237 & -501 & 1.157 & $81 \% 6 \mathrm{~d} 7 \mathrm{~s}\left({ }^{3} \mathrm{D}\right) 7 \mathrm{p}{ }^{4} \mathrm{D}^{\circ}+5 \% 6 \mathrm{~d} 7 \mathrm{~s}\left({ }^{1} \mathrm{D}\right) 7 \mathrm{p}{ }^{2} \mathrm{D}^{\circ}$ \\
\hline $6 \mathrm{~d} 7 \mathrm{~s}\left({ }^{3} \mathrm{D}\right) 7 \mathrm{p}^{2} \mathrm{D}^{\circ}$ & $5 / 2$ & 17950.71 & 19063 & -1112 & 1.223 & $27 \% 6 \mathrm{~d} 7 \mathrm{~s}\left({ }^{3} \mathrm{D}\right) 7 \mathrm{p}{ }^{4} \mathrm{D}^{\circ}+24 \% 6 \mathrm{~d} 7 \mathrm{~s}\left({ }^{3} \mathrm{D}\right) 7 \mathrm{p}{ }^{4} \mathrm{~F}^{\circ}$ \\
\hline $6 \mathrm{~d} 7 \mathrm{~s}\left({ }^{3} \mathrm{D}\right) 7 \mathrm{p}{ }^{4} \mathrm{D}^{\circ}$ & $3 / 2$ & 19012.46 & 20158 & -1146 & 0.992 & $35 \% 6 \mathrm{~d} 7 \mathrm{~s}\left({ }^{3} \mathrm{D}\right) 7 \mathrm{p}{ }^{2} \mathrm{D}^{\circ}+24 \% 6 \mathrm{~d} 7 \mathrm{~s}\left({ }^{1} \mathrm{D}\right) 7 \mathrm{p}{ }^{2} \mathrm{D}^{\circ}+21 \% 6 \mathrm{~d} 7 \mathrm{~s}\left({ }^{3} \mathrm{D}\right) 7 \mathrm{p}{ }^{4} \mathrm{P}^{\circ}$ \\
\hline \multirow[t]{2}{*}{$6 \mathrm{~d} 7 \mathrm{~s}\left({ }^{3} \mathrm{D}\right) 7 \mathrm{p}{ }^{4} \mathrm{D}^{\circ}$} & $5 / 2$ & 21195.87 & 19957 & 1239 & 1.373 & $61 \% 6 \mathrm{~d} 7 \mathrm{~s}\left({ }^{3} \mathrm{D}\right) 7 \mathrm{p}{ }^{4} \mathrm{D}^{\circ}+18 \% 6 \mathrm{~d} 7 \mathrm{~s}\left({ }^{3} \mathrm{D}\right) 7 \mathrm{p}{ }^{4} \mathrm{P}^{\circ}+10 \% 6 \mathrm{~d} 7 \mathrm{~s}\left({ }^{3} \mathrm{D}\right) 7 \mathrm{p}{ }^{2} \mathrm{D}^{\circ}$ \\
\hline & $9 / 2$ & & 21559 & & 1.334 & $98 \% 6 \mathrm{~d} 7 \mathrm{~s}\left({ }^{3} \mathrm{D}\right) 7 \mathrm{p}{ }^{4} \mathrm{~F}^{\circ}$ \\
\hline $6 \mathrm{~d} 7 \mathrm{~s}\left({ }^{3} \mathrm{D}\right) 7 \mathrm{p}{ }^{4} \mathrm{P}^{\circ}$ & $1 / 2$ & 22401.52 & 20944 & 1457 & 2.596 & $95 \% 6 \mathrm{~d} 7 \mathrm{~s}\left({ }^{3} \mathrm{D}\right) 7 \mathrm{p}{ }^{4} \mathrm{P}^{\circ}$ \\
\hline $6 \mathrm{~d} 7 \mathrm{~s}\left({ }^{3} \mathrm{D}\right) 7 \mathrm{p}{ }^{4} \mathrm{P}^{\circ}$ & $3 / 2$ & 22801.10 & 21415 & 1386 & 1.511 & $67 \% 6 \mathrm{~d} 7 \mathrm{~s}\left({ }^{3} \mathrm{D}\right) 7 \mathrm{p}{ }^{4} \mathrm{P}^{\circ}+9 \% 6 \mathrm{~d} 7 \mathrm{~s}\left({ }^{3} \mathrm{D}\right) 7 \mathrm{p}{ }^{4} \mathrm{D}^{\circ}+8 \% 6 \mathrm{~d} 7 \mathrm{~s}\left({ }^{1} \mathrm{D}\right) 7 \mathrm{p}^{2} \mathrm{D}^{\circ}$ \\
\hline $6 \mathrm{~d} 7 \mathrm{~s}\left({ }^{3} \mathrm{D}\right) 7 \mathrm{p}{ }^{4} \mathrm{D}^{\circ}$ & $7 / 2$ & 23475.94 & 21222 & 2254 & 1.402 & $88 \% 6 \mathrm{~d} 7 \mathrm{~s}\left({ }^{3} \mathrm{D}\right) 7 \mathrm{p}{ }^{4} \mathrm{D}^{\circ}+5 \% 6 \mathrm{~d} 7 \mathrm{~s}\left({ }^{3} \mathrm{D}\right) 7 \mathrm{p}{ }^{2} \mathrm{~F}^{\circ}$ \\
\hline $6 \mathrm{~d} 7 \mathrm{~s}\left({ }^{3} \mathrm{D}\right) 7 \mathrm{p}{ }^{4} \mathrm{P}^{\circ}$ & $5 / 2$ & 23898.86 & 22787 & 1112 & 1.317 & $55 \% 6 \mathrm{~d} 7 \mathrm{~s}\left({ }^{3} \mathrm{D}\right) 7 \mathrm{p}{ }^{4} \mathrm{P}^{\circ}+23 \% 6 \mathrm{~d} 7 \mathrm{~s}\left({ }^{1} \mathrm{D}\right) 7 \mathrm{p}^{2} \mathrm{~F}^{\circ}+5 \% 6 \mathrm{~d} 7 \mathrm{~s}\left({ }^{1} \mathrm{D}\right) 7 \mathrm{p}^{2} \mathrm{D}^{\circ}$ \\
\hline $6 \mathrm{~d} 7 \mathrm{~s}\left({ }^{3} \mathrm{D}\right) 7 \mathrm{p}^{2} \mathrm{~F}^{\circ}$ & $5 / 2$ & 23916.84 & 23914 & 3 & 1.048 & $31 \% 6 \mathrm{~d} 7 \mathrm{~s}\left({ }^{1} \mathrm{D}\right) 7 \mathrm{p}^{2} \mathrm{~F}^{\circ}+17 \% 6 \mathrm{~d} 7 \mathrm{~s}\left({ }^{3} \mathrm{D}\right) 7 \mathrm{p}{ }^{4} \mathrm{P}^{\circ}+14 \% 6 \mathrm{~d} 7 \mathrm{~s}\left({ }^{3} \mathrm{D}\right) 7 \mathrm{p}{ }^{2} \mathrm{~F}^{\circ}$ \\
\hline $6 \mathrm{~d} 7 \mathrm{~s}\left({ }^{3} \mathrm{D}\right) 7 \mathrm{p}^{2} \mathrm{~F}^{\circ}$ & $7 / 2$ & 24969.30 & 26001 & -1032 & 1.164 & $53 \% 6 \mathrm{~d} 7 \mathrm{~s}\left({ }^{1} \mathrm{D}\right) 7 \mathrm{p}{ }^{2} \mathrm{~F}^{\circ}+27 \% 6 \mathrm{~d} 7 \mathrm{~s}\left({ }^{3} \mathrm{D}\right) 7 \mathrm{p}{ }^{2} \mathrm{~F}^{\circ}+7 \% 6 \mathrm{~d} 7 \mathrm{~s}\left({ }^{3} \mathrm{D}\right) 7 \mathrm{p}^{4} \mathrm{D}^{\circ}$ \\
\hline $6 \mathrm{~d} 7 \mathrm{~s}\left({ }^{3} \mathrm{D}\right) 7 \mathrm{p}{ }^{2} \mathrm{P}^{\circ}$ & $1 / 2$ & 25729.03 & 26821 & -1092 & 0.661 & $40 \% 6 \mathrm{~d} 7 \mathrm{~s}\left({ }^{1} \mathrm{D}\right) 7 \mathrm{p}{ }^{2} \mathrm{P}^{\circ}+31 \% 6 \mathrm{~d} 7 \mathrm{~s}\left({ }^{3} \mathrm{D}\right) 7 \mathrm{p}^{2} \mathrm{P}^{\circ}+10 \% 6 \mathrm{~d}^{2}\left({ }^{1} \mathrm{D}\right) 7 \mathrm{p}^{2} \mathrm{P}^{\circ}$ \\
\hline $6 \mathrm{~d} 7 \mathrm{~s}\left({ }^{1} \mathrm{D}\right) 7 \mathrm{p}^{2} \mathrm{D}^{\circ}$ & $3 / 2$ & 26066.04 & 25192 & 874 & 0.857 & $35 \% 6 \mathrm{~d} 7 \mathrm{~s}\left({ }^{3} \mathrm{D}\right) 7 \mathrm{p}{ }^{2} \mathrm{D}^{\circ}+35 \% 6 \mathrm{~d} 7 \mathrm{~s}\left({ }^{1} \mathrm{D}\right) 7 \mathrm{p}{ }^{2} \mathrm{D}^{\circ}+16 \% 6 \mathrm{~d}^{2}\left({ }^{3} \mathrm{~F}\right) 7 \mathrm{p}^{2} \mathrm{D}^{\circ}$ \\
\hline $6 \mathrm{~d} 7 \mathrm{~s}\left({ }^{1} \mathrm{D}\right) 7 \mathrm{p}{ }^{2} \mathrm{D}^{\circ}$ & $5 / 2$ & 26533.16 & 25296 & 1237 & 0.919 & $55 \% 6 \mathrm{~d} 7 \mathrm{~s}\left({ }^{3} \mathrm{D}\right) 7 \mathrm{p}^{2} \mathrm{~F}^{\circ}+17 \% 6 \mathrm{~d} 7 \mathrm{~s}\left({ }^{1} \mathrm{D}\right) 7 \mathrm{p}^{2} \mathrm{~F}^{\circ}+8 \% 6 \mathrm{~d} 7 \mathrm{~s}\left({ }^{3} \mathrm{D}\right) 7 \mathrm{p}^{2} \mathrm{D}^{\circ}$ \\
\hline $6 \mathrm{~d} 7 \mathrm{~s}\left({ }^{1} \mathrm{D}\right) 7 \mathrm{p}^{2} \mathrm{~F}^{\circ}$ & $5 / 2$ & 26836.20 & 28619 & -1783 & 1.161 & $33 \% 6 \mathrm{~d} 7 \mathrm{~s}\left({ }^{3} \mathrm{D}\right) 7 \mathrm{p}{ }^{2} \mathrm{D}^{\circ}+32 \% 6 \mathrm{~d} 7 \mathrm{~s}\left({ }^{1} \mathrm{D}\right) 7 \mathrm{p}{ }^{2} \mathrm{D}^{\circ}+16 \% 6 \mathrm{~d}^{2}\left({ }^{3} \mathrm{~F}\right) 7 \mathrm{p}^{2} \mathrm{D}^{\circ}$ \\
\hline $6 \mathrm{~d} 7 \mathrm{~s}\left({ }^{3} \mathrm{D}\right) 7 \mathrm{p}{ }^{2} \mathrm{P}^{\circ}$ & $3 / 2$ & 27009.84 & 27227 & -217 & 1.295 & $70 \% 6 \mathrm{~d} 7 \mathrm{~s}\left({ }^{1} \mathrm{D}\right) 7 \mathrm{p}{ }^{2} \mathrm{P}^{\circ}+11 \% 6 \mathrm{~d}^{2}\left({ }^{1} \mathrm{D}\right) 7 \mathrm{p}^{2} \mathrm{P}^{\circ}+7 \% 6 \mathrm{~d} 7 \mathrm{~s}\left({ }^{1} \mathrm{D}\right) 7 \mathrm{p}^{2} \mathrm{D}^{\circ}$ \\
\hline \multirow[t]{2}{*}{$6 \mathrm{~d} 7 \mathrm{~s}\left({ }^{1} \mathrm{D}\right) 7 \mathrm{p}^{2} \mathrm{~F}^{\circ}$} & $7 / 2$ & 28568.40 & 27050 & 1518 & 1.148 & $44 \% 6 \mathrm{~d} 7 \mathrm{~s}\left({ }^{3} \mathrm{D}\right) 7 \mathrm{p}^{2} \mathrm{~F}^{\circ}+22 \% 6 \mathrm{~d} 7 \mathrm{~s}\left({ }^{1} \mathrm{D}\right) 7 \mathrm{p}^{2} \mathrm{~F}^{\circ}+10 \% 5 \mathrm{f} 7 \mathrm{~s}^{2}{ }^{2} \mathrm{~F}^{\circ}$ \\
\hline & $1 / 2$ & & 29062 & & 0.683 & $39 \% 6 \mathrm{~d} 7 \mathrm{~s}\left({ }^{1} \mathrm{D}\right) 7 \mathrm{p}{ }^{2} \mathrm{P}^{\circ}+26 \% 6 \mathrm{~d} 7 \mathrm{~s}\left({ }^{3} \mathrm{D}\right) 7 \mathrm{p}{ }^{2} \mathrm{P}^{\circ}+19 \% 7 \mathrm{~s}^{2} 8 \mathrm{p}^{2} \mathrm{P}^{\circ}$ \\
\hline $6 \mathrm{~d} 7 \mathrm{~s}\left({ }^{1} \mathrm{D}\right) 7 \mathrm{p}{ }^{2} \mathrm{P}^{\circ}$ & $3 / 2$ & 30396.61 & 30103 & 294 & 1.325 & $43 \% 6 \mathrm{~d} 7 \mathrm{~s}\left({ }^{3} \mathrm{D}\right) 7 \mathrm{p} \mathrm{p}^{2}+35 \% 7 \mathrm{~s}^{2} 8 \mathrm{p}^{2} \mathrm{P}^{\circ}+6 \% 7 \mathrm{~s}^{2} 7 \mathrm{p}^{2} \mathrm{P}^{\circ}$ \\
\hline $6 d^{2}\left({ }^{3} F\right) 7 p^{4} G^{\circ}$ & $5 / 2$ & 31494.68 & 31068 & 427 & 0.614 & $85 \% 6 \mathrm{~d}^{2}\left({ }^{3} \mathrm{~F}\right) 7 \mathrm{p}^{4} \mathrm{G}^{\circ}$ \\
\hline $6 d^{2}\left({ }^{3} F\right) 7 p^{4} G^{\circ}$ & $7 / 2$ & 32219.62 & 33007 & -787 & 0.993 & $93 \% 6 d^{2}\left({ }^{3} F\right) 7 p^{4} G^{\circ}$ \\
\hline $6 d^{2}\left({ }^{3} F\right) 7 p^{4} G^{\circ}$ & $9 / 2$ & 32867.39 & 35080 & -2213 & 1.168 & $94 \% 6 \mathrm{~d}^{2}\left({ }^{3} \mathrm{~F}\right) 7 \mathrm{p}^{4} \mathrm{G}^{\circ}$ \\
\hline $6 d^{2}\left({ }^{3} F\right) 7 p^{4} G^{\circ}$ & $11 / 2$ & 33429.76 & 37381 & -3951 & 1.264 & $92 \% 6 d^{2}\left({ }^{3} F\right) 7 p^{4} G^{\circ}$ \\
\hline
\end{tabular}

${ }^{a}$ From Blaise \& Wyart (1992). ${ }^{b}$ Semi-empirical HFR calculations (present work). ${ }^{c} \Delta E=E_{\text {exp }}-E_{\text {calc }}{ }^{d}$ Landé factor as calculated in the present work. ${ }^{e}$ Only the first three components $\geq 5 \%$ are given. 
P. Quinet et al.: Atomic data for Ra I, Ra II, Ac I and Ac II, Online Material p 6

Table 4. Comparison between experimental and calculated energy levels in Ac II.

\begin{tabular}{|c|c|c|c|c|c|c|}
\hline Designation $^{a}$ & $J$ & $\begin{array}{r}E_{\exp }^{a} \\
\left(\mathrm{~cm}^{-1}\right)\end{array}$ & $\begin{array}{c}E_{\text {calc }}^{b} \\
\left(\mathrm{~cm}^{-1}\right)\end{array}$ & $\begin{array}{r}\Delta E^{c} \\
\left(\mathrm{~cm}^{-1}\right)\end{array}$ & $g^{d}$ & Composition $^{e}$ \\
\hline \multicolumn{7}{|l|}{ Even parity } \\
\hline $7 \mathrm{~s}^{2}{ }^{1} \mathrm{~S}$ & 0 & 0.00 & 0 & 0 & & $95 \% 7 \mathrm{~s}^{2}{ }^{1} \mathrm{~S}$ \\
\hline $6 \mathrm{~d} 7 \mathrm{~s}^{3} \mathrm{D}$ & 1 & 4739.63 & 4688 & 51 & 0.499 & $99 \% 6 \mathrm{~d} 7 \mathrm{~s}{ }^{3} \mathrm{D}$ \\
\hline $6 \mathrm{~d} 7 \mathrm{~s}{ }^{3} \mathrm{D}$ & 2 & 5267.16 & 5352 & -84 & 1.150 & $89 \% 6 \mathrm{~d} 7 \mathrm{~s}{ }^{3} \mathrm{D}+9 \% 6 \mathrm{~d} 7 \mathrm{~s}{ }^{1} \mathrm{D}$ \\
\hline $6 \mathrm{~d} 7 \mathrm{~s}^{3} \mathrm{D}$ & 3 & 7426.52 & 7404 & 23 & 1.334 & $99 \% 6 \mathrm{~d} 7 \mathrm{~s}^{3} \mathrm{D}$ \\
\hline $6 \mathrm{~d} 7 \mathrm{~s}{ }^{1} \mathrm{D}$ & 2 & 9087.54 & 9352 & -265 & 1.007 & $67 \% 6 \mathrm{~d} 7 \mathrm{~s}{ }^{1} \mathrm{D}+18 \% 6 \mathrm{~d}^{2}{ }^{1} \mathrm{D}+10 \% 6 \mathrm{~d} 7 \mathrm{~s}{ }^{3} \mathrm{D}$ \\
\hline $6 d^{2}{ }^{3} \mathrm{~F}$ & 2 & 13236.46 & 13134 & 102 & 0.692 & $92 \% 6 d^{2}{ }^{3} F+6 \% 6 d 7 s{ }^{1} D$ \\
\hline $6 d^{2}{ }^{3} F$ & 3 & 14949.21 & 14970 & -21 & 1.084 & $99 \% 6 \mathrm{~d}^{2}{ }^{3} \mathrm{~F}$ \\
\hline $6 d^{2}{ }^{3} \mathrm{~F}$ & 4 & 16756.90 & 16839 & -82 & 1.230 & $91 \% 6 d^{2}{ }^{3} \mathrm{~F}+8 \% 6 \mathrm{~d}^{2}{ }^{1} \mathrm{G}$ \\
\hline $6 d^{2}{ }^{3} \mathrm{P}$ & 0 & 17737.10 & 17767 & -30 & & $91 \% 6 \mathrm{~d}^{2}{ }^{3} \mathrm{P}+6 \% 6 \mathrm{~d}^{2}{ }^{1} \mathrm{~S}$ \\
\hline $6 d^{2}{ }^{3} \mathrm{P}$ & 1 & 19015.32 & 19055 & -40 & 1.501 & $98 \% 6 \mathrm{~d}^{2}{ }^{3} \mathrm{P}$ \\
\hline $6 d^{2}{ }^{1} \mathrm{D}$ & 2 & 19203.02 & 19137 & 66 & 1.312 & $62 \% 6 d^{2}{ }^{3} \mathrm{P}+25 \% 6 \mathrm{~d}^{2}{ }^{1} \mathrm{D}+7 \% 6 \mathrm{~d} 7 \mathrm{~s}{ }^{1} \mathrm{D}$ \\
\hline $6 d^{21} G$ & 4 & 20848.23 & 20838 & 10 & 1.021 & $90 \% 6 d^{2}{ }^{1} \mathrm{G}+8 \% 6 \mathrm{~d}^{2}{ }^{3} \mathrm{~F}$ \\
\hline \multirow[t]{4}{*}{$6 \mathrm{~d}^{2}{ }^{3} \mathrm{P}$} & 2 & 22199.45 & 22122 & 77 & 1.173 & $52 \% 6 \mathrm{~d}^{2}{ }^{1} \mathrm{D}+35 \% 6 \mathrm{~d}^{2}{ }^{3} \mathrm{P}+8 \% 6 \mathrm{~d} 7 \mathrm{~s}{ }^{1} \mathrm{D}$ \\
\hline & 0 & & 28072 & & & $82 \% 6 \mathrm{~d}^{2}{ }^{1} \mathrm{~S}+7 \% 6 \mathrm{~d}^{2}{ }^{3} \mathrm{P}$ \\
\hline & 0 & & 51281 & & & $83 \% 7 \mathrm{p}^{2}{ }^{3} \mathrm{P}+8 \% 7 \mathrm{p}^{2}{ }^{1} \mathrm{~S}$ \\
\hline & 2 & & 51348 & & 1.079 & $41 \% 6 \mathrm{~d} 8 \mathrm{~s}^{3} \mathrm{D}+35 \% 6 \mathrm{~d} 8 \mathrm{~s}{ }^{1} \mathrm{D}+13 \% 7 \mathrm{~s} 7 \mathrm{~d}{ }^{1} \mathrm{D}$ \\
\hline \multirow[t]{3}{*}{$7 \mathrm{~s} 8 \mathrm{~s}^{3} S$} & 1 & 51680.55 & 51470 & 211 & 1.989 & $94 \% 7 \mathrm{~s} 8 \mathrm{~s}^{3} \mathrm{~S}$ \\
\hline & 1 & & 51574 & & 0.510 & $90 \% 6 \mathrm{~d} 8 \mathrm{~s}{ }^{3} \mathrm{D}$ \\
\hline & 3 & & 52816 & & 0.809 & $46 \% 5 f 7 p^{3} G+31 \% 6 d 7 d^{3} G+12 \% 5 f 7 p{ }^{1} F$ \\
\hline $7 \mathrm{~s} 8 \mathrm{~s}{ }^{1} \mathrm{~S}$ & 0 & 53374.01 & 53304 & 70 & & $94 \% 7 \mathrm{~s} 8 \mathrm{~s}^{1} \mathrm{~S}$ \\
\hline \multicolumn{7}{|c|}{ Odd parity } \\
\hline $7 \mathrm{~s} 7 \mathrm{p}^{3} \mathrm{P}^{\circ}$ & 0 & 20956.40 & 20980 & -24 & & $98 \% 7 \mathrm{~s} 7 \mathrm{p}^{3} \mathrm{P}^{\circ}$ \\
\hline $7 \mathrm{~s} 7 \mathrm{p}^{3} \mathrm{P}^{\circ}$ & 1 & 22180.52 & 22147 & 34 & 1.463 & $90 \% 7 \mathrm{~s} 7 \mathrm{p}^{3} \mathrm{P}^{\circ}+5 \% 7 \mathrm{~s} 7 \mathrm{p}^{1} \mathrm{P}^{\circ}$ \\
\hline $7 \mathrm{~s} 7 \mathrm{p}^{3} \mathrm{P}^{\circ}$ & 2 & 26446.96 & 26446 & 1 & 1.494 & $95 \% 7 \mathrm{~s} 7 \mathrm{p}^{3} \mathrm{P}^{\circ}$ \\
\hline $6 \mathrm{~d} 7 \mathrm{p}^{3} \mathrm{~F}^{\circ}$ & 2 & 28201.11 & 27555 & 646 & 0.714 & $55 \% 6 \mathrm{~d} 7 \mathrm{p}^{3} \mathrm{~F}^{\circ}+32 \% 5 \mathrm{f} 7 \mathrm{~s}^{3} \mathrm{~F}^{\circ}+10 \% 6 \mathrm{~d} 7 \mathrm{p}^{1} \mathrm{D}^{\circ}$ \\
\hline $6 \mathrm{~d} 7 \mathrm{p}$ & 1 & 29250.40 & 29289 & -39 & 0.892 & $36 \% 6 \mathrm{~d} 7 \mathrm{p}{ }^{1} \mathrm{P}^{\circ}+30 \% 6 \mathrm{~d} 7 \mathrm{p}^{3} \mathrm{D}^{\circ}+22 \% 7 \mathrm{~s} 7 \mathrm{p}{ }^{1} \mathrm{P}^{\circ}$ \\
\hline $5 \mathrm{f} 7 \mathrm{~s}^{1} \mathrm{~F}^{\circ}$ & 3 & 29881.09 & 29753 & 128 & 1.067 & $46 \% 5 f 7 s^{3} \mathrm{~F}^{\circ}+33 \% 6 \mathrm{~d} 7 \mathrm{p}^{3} \mathrm{~F}^{\circ}+16 \% 5 \mathrm{f} 7 \mathrm{~s}^{1} \mathrm{~F}^{\circ}$ \\
\hline $6 \mathrm{~d} 7 \mathrm{p}$ & 3 & 31174.60 & 31409 & -234 & 1.042 & $44 \% 5 f 7 s^{1} \mathrm{~F}^{\circ}+28 \% 6 \mathrm{~d} 7 \mathrm{p}^{1} \mathrm{~F}^{\circ}+17 \% 6 \mathrm{~d} 7 \mathrm{p}^{3} \mathrm{~F}^{\circ}$ \\
\hline $6 \mathrm{~d} 7 \mathrm{p}^{1} \mathrm{D}^{\circ}$ & 2 & 31878.87 & 32064 & -185 & 0.961 & $64 \% 6 \mathrm{~d} 7 \mathrm{p}^{1} \mathrm{D}^{\circ}+23 \% 5 \mathrm{f} 7 \mathrm{~s}^{3} \mathrm{~F}^{\circ}+6 \% 6 \mathrm{~d} 7 \mathrm{p}^{3} \mathrm{P}^{\circ}$ \\
\hline $5 f 7 s^{3} \mathrm{~F}^{\circ}$ & 4 & 32965.55 & 32902 & 64 & 1.251 & $62 \% 5 f 7 s^{3} \mathrm{~F}^{\circ}+38 \% 6 \mathrm{~d} 7 \mathrm{p}^{3} \mathrm{~F}^{\circ}$ \\
\hline $6 \mathrm{~d} 7 \mathrm{p}^{3} \mathrm{D}^{\circ}$ & 2 & 33304.96 & 33485 & -180 & 1.184 & $83 \% 6 \mathrm{~d} 7 \mathrm{p}^{3} \mathrm{D}^{\circ}+7 \% 6 \mathrm{~d} 7 \mathrm{p}^{3} \mathrm{P}^{\circ}$ \\
\hline $6 \mathrm{~d} 7 \mathrm{p}^{3} \mathrm{D}^{\circ}$ & 1 & 33388.61 & 33271 & 118 & 0.684 & $61 \% 6 \mathrm{~d} 7 \mathrm{p}^{3} \mathrm{D}^{\circ}+23 \% 7 \mathrm{~s} 7 \mathrm{p}^{1} \mathrm{P}^{\circ}+11 \% 6 \mathrm{~d} 7 \mathrm{p}^{1} \mathrm{P}^{\circ}$ \\
\hline $6 \mathrm{~d} 7 \mathrm{p}^{3} \mathrm{D}^{\circ}$ & 3 & 35144.35 & 35903 & -759 & 1.289 & $80 \% 6 \mathrm{~d} 7 \mathrm{p}^{3} \mathrm{D}^{\circ}+10 \% 5 \mathrm{f} 7 \mathrm{~s}^{1} \mathrm{~F}^{\circ}+6 \% 5 \mathrm{f} 6 \mathrm{~d}^{\frac{1}{3}} \mathrm{D}^{\circ}$ \\
\hline $6 \mathrm{~d} 7 \mathrm{p}$ & 2 & 35397.12 & 35729 & -332 & 0.741 & $37 \% 5 f 7 s^{3} F^{\circ}+36 \% 6 d 7 p^{3} F^{\circ}+11 \% 5 f 6 d^{3} F^{\circ}$ \\
\hline $6 \mathrm{~d} 7 \mathrm{p}^{3} \mathrm{P}^{\circ}$ & 0 & 36780.01 & 36787 & -7 & & $85 \% 6 \mathrm{~d} 7 \mathrm{p}^{3} \mathrm{P}^{\circ}+13 \% 5 \mathrm{f} 6 \mathrm{~d}^{3} \mathrm{P}^{\circ}$ \\
\hline $6 \mathrm{~d} 7 \mathrm{p}^{3} \mathrm{P}^{\circ}$ & 1 & 36855.50 & 36948 & -92 & 1.445 & $78 \% 6 \mathrm{~d} 7 \mathrm{p}^{3} \mathrm{P}^{\circ}+12 \% 5 \mathrm{f} 6 \mathrm{~d}^{3} \mathrm{P}^{\circ}+6 \% 7 \mathrm{~s} 7 \mathrm{p}^{1} \mathrm{P}^{\circ}$ \\
\hline $6 \mathrm{~d} 7 \mathrm{p}$ & 3 & 36972.94 & 37288 & -315 & 1.084 & $40 \% 6 \mathrm{~d} 7 \mathrm{p}^{3} \mathrm{~F}^{\circ}+38 \% 5 \mathrm{f} 7 \mathrm{~s}^{3} \mathrm{~F}^{\circ}+16 \% 5 \mathrm{f} 6 \mathrm{~d}^{3} \mathrm{~F}^{\circ}$ \\
\hline $6 \mathrm{~d} 7 \mathrm{p}^{3} \mathrm{P}^{\circ}$ & 2 & 38371.64 & 38364 & 8 & 1.407 & $68 \% 6 \mathrm{~d} 7 \mathrm{p}^{3} \mathrm{P}^{\circ}+12 \% 6 \mathrm{~d} 7 \mathrm{p}^{1} \mathrm{D}^{\circ}+11 \% 5 \mathrm{f} 6 \mathrm{~d}^{3} \mathrm{P}^{\circ}$ \\
\hline $6 \mathrm{~d} 7 \mathrm{p}^{3} \mathrm{~F}^{\circ}$ & 4 & 39119.02 & 38958 & 161 & 0.852 & $81 \% 5 f 6 d^{3} \mathrm{H}^{\circ}+13 \% 5 f 6 d^{1} G^{\circ}$ \\
\hline $5 \mathrm{f} 6 \mathrm{~d}^{3} H^{\circ}$ & 4 & 39807.14 & 39640 & 167 & 1.206 & $41 \% 6 \mathrm{~d} 7 \mathrm{p}^{3} \mathrm{~F}^{\circ}+26 \% 5 \mathrm{f} 7 \mathrm{~s}^{3} \mathrm{~F}^{\circ}+23 \% 5 \mathrm{f} 6 \mathrm{~d}^{3} \mathrm{~F}^{\circ}$ \\
\hline $5 f 6 d^{3} F^{\circ}$ & 2 & 41578.57 & 41608 & -29 & 0.739 & $68 \% 5 f 6 d^{3} F^{\circ}+20 \% 5 f 6 d^{1} D^{\circ}$ \\
\hline $5 f 6 d^{1} \mathrm{G}^{\circ}$ & 4 & 41627.79 & 41554 & 74 & 1.004 & $79 \% 5 \mathrm{f} 6 \mathrm{~d}^{1} \mathrm{G}^{\circ}+10 \% 5 \mathrm{f} 6 \mathrm{~d}^{3} H^{\circ}+6 \% 6 \mathrm{~d} 7 \mathrm{p}^{3} \mathrm{~F}^{\circ}$ \\
\hline \multirow[t]{2}{*}{$6 \mathrm{~d} 7 \mathrm{p}^{1} \mathrm{~F}^{\circ}$} & 3 & 41937.05 & 41686 & 251 & 1.016 & $47 \% 6 \mathrm{~d} 7 \mathrm{p}{ }^{1} \mathrm{~F}^{\circ}+22 \% 5 \mathrm{f} 6 \mathrm{~d}^{1} \mathrm{~F}^{\circ}+21 \% 5 \mathrm{f} 7 \mathrm{~s}^{1} \mathrm{~F}^{\circ}$ \\
\hline & 6 & & 43001 & & 1.167 & $100 \% 5 \mathrm{f}^{1} \mathrm{~d}^{3} H^{\circ}$ \\
\hline $5 f 6 d^{3} F^{\circ}$ & 3 & 43275.85 & 43419 & -143 & 1.083 & $83 \% 5 f 6 d^{3} F^{\circ}+9 \% 6 d 7 p{ }^{3} F^{\circ}+6 \% 5 f 7 s^{3} F^{\circ}$ \\
\hline $6 \mathrm{~d} 7 \mathrm{p}$ & 1 & 44199.94 & 44233 & -33 & 1.014 & $30 \% 5 f 6 d^{1} \mathrm{P}^{\circ}+30 \% 7 \mathrm{~s} 7 \mathrm{p}^{1} \mathrm{P}^{\circ}$ \\
\hline $5 \mathrm{f} 6 \mathrm{~d}^{1} \mathrm{D}^{\circ}$ & 2 & 44705.33 & 44672 & 33 & 0.944 & $70 \% 5 f 6 d^{1} D^{\circ}+19 \% 5 f 6 d^{3} F^{\circ}$ \\
\hline $5 f 6 d^{3} F^{\circ}$ & 4 & 45040.30 & 45283 & -242 & 1.238 & $74 \% 5 f 6 d^{3} F^{\circ}+13 \% 6 d 7 p^{3} F^{\circ}+8 \% 5 f 7 s^{3} F^{\circ}$ \\
\hline $5 f 6 d^{3} \mathrm{G}^{\circ}$ & 3 & 45807.06 & 45948 & -141 & 0.759 & $96 \% 5 \mathrm{f}^{2} \mathrm{~d}^{3} \mathrm{G}^{\circ}$ \\
\hline $5 f 6 d^{3} G^{\circ}$ & 4 & 47427.67 & 47422 & 6 & 1.050 & $99 \% 5 \mathrm{f}^{6} \mathrm{~d}^{3} \mathrm{G}^{\circ}$ \\
\hline $5 \mathrm{f} 6 \mathrm{~d}^{3} \mathrm{D}^{\circ}$ & 1 & 48518.41 & 48507 & 11 & 0.552 & $87 \% 5 \mathrm{f}^{6} \mathrm{~d}^{3} \mathrm{D}^{\circ}$ \\
\hline $5 f 6 d^{3} G^{\circ}$ & 5 & 49151.54 & 48994 & 157 & 1.198 & $99 \% 5 \mathrm{f}^{6} \mathrm{~d}^{3} \mathrm{G}^{\circ}$ \\
\hline $5 \mathrm{f} 6 \mathrm{~d}^{3} \mathrm{D}^{\circ}$ & 2 & 49479.05 & 49583 & -104 & 1.170 & $90 \% 5 f 6 d^{3} D^{\circ}+5 \% 6 d 7 p^{3} D^{\circ}$ \\
\hline $5 \mathrm{f} 6 \mathrm{~d}^{3} \mathrm{P}^{\circ}$ & 0 & 49780.60 & 49932 & -151 & & $85 \% 5 f 6 d^{3} \mathrm{P}^{\circ}+12 \% 6 \mathrm{~d} 7 \mathrm{p}^{3} \mathrm{P}^{\circ}$ \\
\hline $5 f 6 d^{3} D^{\circ}$ & 3 & 50059.70 & 50151 & -91 & 1.280 & $79 \% 5 f 6 d^{3} D^{\circ}+11 \% 5 f 6 d^{1} F^{\circ}$ \\
\hline $5 f 6 d^{3} P^{\circ}$ & 1 & 50235.60 & 50012 & 224 & 1.439 & $78 \% 5 f 6 d^{3} \mathrm{P}^{\circ}+10 \% 6 \mathrm{~d} 7 \mathrm{p}{ }^{3} \mathrm{P}^{\circ}$ \\
\hline $5 \mathrm{f} 6 \mathrm{~d}^{3} \mathrm{P}^{\circ}$ & 2 & 51257.51 & 51208 & 50 & 1.481 & $82 \% 5 f 6 d^{3} \mathrm{P}^{\circ}+11 \% 6 \mathrm{~d} 7 \mathrm{p}^{3} \mathrm{P}^{\circ}$ \\
\hline
\end{tabular}


P. Quinet et al.: Atomic data for Ra I, Ra II, Ac I and Ac II, Online Material $p 7$

Table 4. continued.

\begin{tabular}{lcrrrrl}
\hline \hline Designation $^{a}$ & $J$ & $\begin{array}{r}E_{\text {exp }}^{a} \\
\left(\mathrm{~cm}^{-1}\right)\end{array}$ & $\begin{array}{r}E_{\text {calc }}^{b} \\
\left(\mathrm{~cm}^{-1}\right)\end{array}$ & $\begin{array}{r}\Delta E^{c} \\
\left(\mathrm{~cm}^{-1}\right)\end{array}$ & $g^{d}$ & Composition \\
\hline $5 \mathrm{f} 6 \mathrm{~d}{ }^{1} \mathrm{~F}^{\circ}$ & 3 & 53255.30 & 53095 & 160 & 1.048 & $62 \% 5 \mathrm{f} 6 \mathrm{~d}{ }^{1} \mathrm{~F}^{\circ}+14 \% 5 \mathrm{f}^{\circ} \mathrm{d}^{3} \mathrm{D}^{\circ}+10 \% 6 \mathrm{~d} 7 \mathrm{p}^{1} \mathrm{~F}^{\circ}$ \\
& 5 & & 55784 & & 1.002 & $97 \% 5 \mathrm{f} 6 \mathrm{~d}^{1} \mathrm{H}^{\circ}$ \\
$5 \mathrm{f} 6 \mathrm{~d}{ }^{1} \mathrm{P}^{\circ}$ & 1 & 56152.2 & 56320 & -168 & 1.014 & $48 \% 5 \mathrm{f} 6 \mathrm{~d}^{1} \mathrm{P}^{\circ}+15 \% 7 \mathrm{~s} 8 \mathrm{p}{ }^{1} \mathrm{P}^{\circ}+11 \% 6 \mathrm{~d} 8 \mathrm{p}{ }^{1} \mathrm{P}^{\circ}$ \\
\hline
\end{tabular}

${ }^{a}$ From Blaise \& Wyart (1992). ${ }^{b}$ Semi-empirical HFR calculations (present work) ${ }^{c} \Delta E=E_{\text {exp }}-E_{\text {calc }} \cdot{ }^{d}$ Landé factor as calculated in the present work. ${ }^{e}$ Only the first three components $\geq 5 \%$ are given. 